NBER WORKING PAPER SERIES

\title{
LOCAL OVERWEIGHTING AND UNDERPERFORMANCE: EVIDENCE FROM LIMITED PARTNER PRIVATE EQUITY INVESTMENTS
}

\author{
Yael V. Hochberg \\ Joshua D. Rauh \\ Working Paper 17122 \\ http://www.nber.org/papers/w17122
NATIONAL BUREAU OF ECONOMIC RESEARCH
1050 Massachusetts Avenue
Cambridge, MA 02138
June 2011

We are grateful to Ed Glaeser, Victoria Ivashina, Josh Pollet, and Jules van Binsbergen for very helpful comments and discussions, as well as seminar participants at Northwestern University, Oxford University, the Federal Reserve Bank of Chicago, DePaul University, the University of Florida, Michigan State University, the University of British Columbia, Yale University, and the University of Hong Kong. Hochberg and Rauh gratefully acknowledge funding from the Zell Center for Risk Research at the Kellogg School of Management. Hochberg gratefully acknowledges funding from the Heizer Center for Private Equity and Venture Capital at the Kellogg School of Management. Address correspondence to: y-hochberg@kellogg.northwestern.edu (Hochberg), joshua-rauh@ @ellogg.northwestern.edu (Rauh). The views expressed herein are those of the authors and do not necessarily reflect the views of the National Bureau of Economic Research.

NBER working papers are circulated for discussion and comment purposes. They have not been peerreviewed or been subject to the review by the NBER Board of Directors that accompanies official NBER publications.

(C) 2011 by Yael V. Hochberg and Joshua D. Rauh. All rights reserved. Short sections of text, not to exceed two paragraphs, may be quoted without explicit permission provided that full credit, including (C) notice, is given to the source. 
Local Overweighting and Underperformance: Evidence from Limited Partner Private Equity Investments

Yael V. Hochberg and Joshua D. Rauh

NBER Working Paper No. 17122

June 2011

JEL No. G11,G23,G24,M13

\begin{abstract}
Institutional investors of all types exhibit substantial home-state bias when investing in private equity (PE) funds. This effect is particularly pronounced for public pension funds, where the local overweighting amounts to $9.7 \%$ of the private equity portfolio on average, based on 5-year rolling average benchmarks. Public pension funds' own-state investments perform significantly worse than their out-of-state investments, an average of 3-4 percentage points of net IRR per year, and those that that overweight their portfolios towards home-state investments also perform worse overall. These underperformance patterns are not evident for other types of institutional investors, such as endowments, foundations and corporate pension funds, and we do not observe similar overweighting or underperformance of investments in neighboring states. Overweighting in home state investments by public pension funds is greater in states with higher levels of corruption, although there is no positive correlation of underperformance with corruption for these investors. The overweighting and underperformance of local investments cost public pension funds between $\$ 0.9$ and $\$ 1.2$ billion per year, depending on the benchmark.
\end{abstract}

Yael V. Hochberg

Kellogg School of Management

Northwestern University

2001 Sheridan Road

Evanston, IL 60208

and NBER

y-hochberg@kellogg.northwestern.edu

Joshua D. Rauh

Kellogg School of Management

Northwestern University

2001 Sheridan Road

Evanston, IL 60208

and NBER

joshua-rauh@kellogg.northwestern.edu 


\section{Introduction}

Institutional investor asset allocations and performance have come under increased scrutiny in recent years. In particular, public institutional investors have faced greater pressure to disclose their private equity fund holdings and performance. Key legal cases, such as the 2002 suit by the San Jose Mercury News filed against the California Public Employees' Retirement System (CalPERS) to force it to disclose its Private Equity (PE) ${ }^{1}$ investments and performance, have stirred the public debate over the level of transparency necessary or desirable when public funds are invested.

A significant and growing literature in financial economics seeks to understand the investment decisions and subsequent performance of institutional investors. Institutional investors as a group vary substantially from retail investors, but also exhibit systematic differences across institutional types in returns and investment strategies (Lerner, Schoar and Wongsunwai (2007)). Relatively few empirical papers, however, have considered the asset allocation choices of institutional investors, and more specifically, how they choose particular investments within asset classes. ${ }^{2}$ In this paper, we address this question in the context of PE, examining allocations to and performance of limited partner (LP) investments. ${ }^{3}$ Specifically, we attempt to quantify the extent and costs of a particular investment bias, the preference for homestate investments.

A preference for geographically local equity investing by managers of domestic public equity within the U.S. has been documented by Coval and Moskowitz (1999), who show that the average U.S. mutual fund manager invests in companies that are physically closer by around $10 \%$ than the average firm that could have been held in the portfolio. In contemporaneous work, Brown, Pollet and Weisbenner (2011) document that state pension plans that actively manage their own stock portfolios overweight the holdings of stocks of companies that are headquartered in-state, suggesting that this sort of home bias is likely relevant for at least some classes of institutional investors other than mutual funds. The possibility of home bias in the selection of

\footnotetext{
${ }^{1}$ Throughout this paper, we will use the term 'private equity' or 'PE' to refer to the general class of private investment funds we examine, which includes Buyout, Venture Capital, Real Estate Private Equity, etc.

${ }^{2}$ Notable exceptions include Coval and Moskowitz (1999, 2001), Baik, Kang and Kim (2009) and Brown, Pollet and Weisbenner (2011).

${ }^{3}$ We note that throughout the remainder of this paper, we will interchangeably use the terms 'institutional investors' and Limited Partners (LPs), as well as the terms 'PE fund managers' and General Partners (GPs).
} 
PE investments, in particular, is a concern in light of evidence in Lerner, Schoar and Wongsunwai (2007) that suggests public pension funds underperform other types of LPs in their in-state PE fund investments.

To examine institutional investor tendencies towards home-state PE investing, we employ an extensive dataset of limited partner (LP) investments in private equity (PE) funds over the last 30 years. Combining these data with data on PE fund performance and location, we examine institutional investor allocations to home-state and out-of state PE funds, as well as their performance on those investments. As we are primarily interested in the location of the GPswho receive the fee income from the investment-we focus on the location of the fund GP, rather than on where the capital is deployed by the GP. ${ }^{4}$

Our analysis suggests that institutional investors of all types (endowments, foundations, public and corporate pension funds) exhibit substantial home bias in their PE portfolios. On average, an excess 8.1 percentage points of the investments in institutional PE portfolios are in funds headquartered in their own state, relative to a given state's share in the population of investments by out-of-state LPs. For public pension funds, however, this over-allocation to instate investment funds is substantially larger. Public pension funds, on average, over-allocate to home-state funds by 9.7 percentage points of the investments in their portfolio, measured relative to their home state's share of the population of funds using 5-year rolling periods. In contrast, home-state over-allocation by other types of institutional investors averages 3-7 percentage points. ${ }^{5}$

One possibility that would explain this overweighting is that public pension funds may be able to make use of local connections, networks and political access to gain better information than out-of-state investors on the prospects of funds located in their home-states, or to gain

\footnotetext{
${ }^{4}$ Data on the underlying investments are not available for most of our sample. It is well established that venture capital investment are made locally to the fund (Sorenson and Stuart (2001)), and there is some evidence that private real estate funds are also geographically specialized (Hochberg and Muhlhofer (2011)). In contrast, we speculate that buyout funds and funds in the 'other' category are probably less likely to invest locally.

${ }^{5}$ Data on actual dollar value allocations to funds is only available for a little over half of the full sample of investments, and coverage on these commitments is particularly poor for the non-public-pension LP classes. In order to exploit the full richness of the different types of institutional investors in the sample, our headline results employ the full sample and treat the investments as all of equal size, effectively equal-weighting the investments. However, we also show that the main results all go through for the categories with sufficient coverage if one focuses only on the smaller sample of investments for which the dollar value of the LP commitment is available (calculating overweighting as a share of total known commitments and value-weighting all performance regressions by the size of the commitment.)
} 
access to more and better funds in their home-states. If so, we would expect the in-state investments made by local public pension funds to perform better than the investments made in their home-state by out-of-state investors who lack such access. We may even observe that the in-state investments made by local public pension funds perform better than the investments made by these pension funds in out-of-state funds; this appears to be the case for public equity investments by state public pension funds, as documented by Brown et al (2011). Furthermore, Coval and Moskowitz (2001) find that U.S. mutual fund managers of public equities earn abnormal positive returns in their local investments in public equities, primarily due to informational advantages. Such informational advantages might be expected to be particularly strong in the realm of private equity, an investment setting characterized by substantial asymmetric information.

When we examine the performance of in-state versus out of state private equity investments, however, we find that public pension funds perform worse by 5.5 percentage points on average on their in-state investments than on the investments they make in out-of-state funds, consistent with the findings in Lerner, Schoar and Wongsunwai (2007). Additionally, we find that public pension funds' performance on in-state investments is worse by 3.6 percentage points compared to investments made by out-of-state LPs in the public pension fund's home state. Thus, the overweighting of public pension fund portfolios in home-state investments does not appear to be due to superior information regarding home-state fund prospects. This contrasts with the findings in Brown et al (2011), who find that state pension funds outperform in their instate public equity investments. Furthermore, this effect does not appear likely to be related to uncertainty aversion due to distance or lack of familiarity (Epstein and Miao (2003)), as there is no difference in performance between out-of-state investments made by public pension fund LPs in immediately neighboring states and those made in non-neighboring states.

When we perform a similar analysis for other types of institutional investors, we do not observe significant performance differences of these types, suggesting that despite evidence of some level of home-state bias in their investment choices, their performance is not adversely affected. The overweighting of public pension LPs in poorly performing local investments is particularly striking when one considers that risk management incentives should give public pension LPs a strong motivation against local concentration. If the performance of local investments is correlated with local economic conditions, then declines in the value of these local 
investments will come exactly at times when state revenues are down and pension funding is most costly.

Why do public pension funds overweight home-state investments with poor performance? Home-state investments are often justified in the context of Economically Targeted Investment (ETI) programs, so a natural hypothesis is that public pension systems are subject to political pressures to invest in their home state. These pressures may be higher in states where self-dealing, corruption and quid pro quo activity is more commonplace. To explore this hypothesis, we relate overweighting in home-state investments to commonly accepted measures of state-level corruption. We find that home-state overweighting by public pension funds is indeed higher in states with greater corruption. In contrast, higher state-level corruption appears to be unrelated to home bias for public institution endowments and foundations, but is associated with lower home-state overweighting for private institution endowments. When we relate the performance of in-state investments to state-level corruption, we find that public pension fund performance on home-state investments does not decrease in the level of corruption (and may in fact increase). ${ }^{6}$ However, we find that the performance of in-state investments for other types of institutions decreases with increased corruption at the state level.

Our final analysis attempts to quantify the hypothetical cost of such home bias by public pension funds. Our calculations suggest that if each public pension LP had performed as well on its in-state investments as out-of-state public pension LPs performed on investments in the same state, the public pension LPs would have reaped $\$ 1.23$ billion annually in additional returns. However, public pension funds that overweight in-state PE also tend to perform somewhat more poorly than other public pension funds when investing out of state. That is, they tend to be slightly worse investors overall. As a result, if each public pension LP had performed as well (and only as well) on its in-state investments as it did out of state, then the total benefit would only be $\$ 0.92$ billion. Averaged equally across the 50 states, the financial effects of these biases represent $0.5-0.6 \%$ of the assets in the private equity programs per year and $1.3-1.8 \%$ of annual contributions to the pension funds. While for some states the costs are quite low, for others such

\footnotetext{
${ }^{6}$ The direction of this effect is consistent with findings for public equity investments by state pension funds in Brown et al (2011), who find that the over-performance of in-state public equity investments by state pension funds is greater in states with higher levels of corruption.

${ }^{7}$ We also examined the correlation between corruption measures and the governance characteristics of public pension systems, including the share of the public pension investment boards that are appointed by government officials, but found little in the way of explanatory patterns.
} 
as Massachusetts and California they appear high as a share of total PE assets and annual contributions.

A caveat to this cost analysis is that data on actual dollar value allocations to funds is only available for a little over half of our sample. In our main calculations, we thus necessarily must make some assumptions about the relative portion of the portfolio dedicated to any individual fund in our sample, assuming that fund investments are of equal size. As an alternative, we have performed value-weighted cost analysis using only the investments for which commitment levels are available, and then extrapolating to the rest of the PE portfolio. The results are highly robust to considering the relative size of investments in this way, and in fact the costs become around 50\% larger. However, the selection in disclosure of commitment levels in some key states (particularly New York) appears to favor the worse-performing investments, suggesting that the equal-weighted cost analysis provides a more accurate picture.

Notably, our analysis does not address the welfare implications of home-state investments by public pension funds. As noted by Lerner, Schoar and Wongsunwai (2007), public pension funds may face political pressures to invest in in-state funds in an effort to support the local economy even if doing so reduces return on investment. It is possible that positive externalities for residents, taxpayers and public sector retirees due to the local economic development resulting from these investments may offset the lower returns earned by the public pension fund. As such, we cannot say unilaterally that the home bias and underperformance on home-state investments documented by our analysis is suboptimal. Rather, we document the extent and potential financial effect of the home bias, and leave explorations of net welfare to future research. We note that the overweighting and underperformance of public pension funds is largest in venture capital and real estate, where, in contrast to leveraged buyouts, positive externalities for local economic development are more plausible.

The contribution of our work is fourfold. First, to the best of our knowledge, this is the first study to perform a detailed examination of home bias in LP investments in the PE industry. We show that LPs in general, and public pension funds in particular, overweight their investments in their home state, and document the costs associated with such bias. Our work is thus related more generally to the literature on limited partner (LP) investments in private equity funds. Gompers and Lerner (1996) and Lerner and Schoar (2004) examine the contracts entered into between investors and funds, and how they are affected by the nature of both the targeted 
investments and the LPs. Lerner, Schoar and Wongsunwai (2007) explore heterogeneity in the returns that different classes of institutional investors earn when investing in private equity and suggest that LPs vary in their level of sophistication. Hochberg, Ljungqvist and VissingJorgensen (2010) model the investment and reinvestment relationship between VC funds and their limited partners in a setting with informational holdup. Large open questions remain, however, as to the drivers and consequences of the decisions by individual LPs to invest in private equity funds, and our work sheds some light on these open issues. ${ }^{8}$

A second and related contribution of our work is to expand upon and shed light on a possible contributor to the limited partner performance puzzle documented by Lerner, Schoar and Wongsunwai (2007). Lerner, Schoar and Wongsunwai (2007) document that endowments earn much higher returns on their PE investments than do other types of institutional investors While Lerner et al show that endowment outperformance is not due solely to regional investments, our results suggest that the underperformance of local investments is nonetheless an important aspect of the relatively poor performance of public pension funds.

A third contribution is to the literature on the local bias for institutional investors, such as French and Poterba (1991), and Coval and Moskowitz (1999, 2001). ${ }^{9}$ Closest to our work in spirit is contemporaneous work by Brown, Pollet and Weisbenner (2011), who examine public equity investments by 20 state pension plans who actively manage their own public equity portfolios. In contrast to Brown et al (2011), we focus on all classes of institutional investors, and examine PE investments rather than publicly traded stock holdings. While both our analysis and that of Brown et al (2011) suggest that public pension funds exhibit substantial home bias in their investment choices, and that this home bias is larger in states with higher levels of corruption, Brown et al (2011) find that public pension funds outperform on their in-state investments, whereas we find that public pensions perform worse on their in-state investments. The corruption results of both our paper and the Brown et al (2011) paper suggest that further

\footnotetext{
${ }^{8}$ A large literature, beginning with Kaplan and Schoar (2005), explores the performance of private equity funds and investments and the relationship between performance and subsequent fundraising. Notable papers include Jones and Rhodes-Kropf (2003), Ljungqvist and Richardson (2003), Cochrane (2005), Korteweg and Sorensen (2010), Quigley and Woodward (2003), Gottschalg and Phalippou (2009), and Hochberg, Ljungqvist and Vissing-Jorgensen (2010).

${ }^{9}$ Other related work in this includes Strong and Xu (2003), who find that international home bias is a function of optimistic attitudes about home country performance, and Graham, Harvey and Huang (2009), who show that local bias is correlated with lower self-confidence regarding investment competence.
} 
examination of the relationship between pension fund (and state-level) governance and public pension investments is warranted.

Relatedly, our final contribution is thus to an emerging literature on public pension fund governance. Public pension systems are underfunded by \$3 trillion (Novy-Marx and Rauh (2010)) and operate under an accounting regime that rewards the taking of risks that allow funds to assume high expected returns. This might be expected to push funds towards riskier investment categories. The relation between public pension fund governance and overall performance has been studied by Mitchell and Hsin (1994) and Coronado, Engen, and Knight (2003). An important question that we are addressing in ongoing research is the extent to which our state level corruption measures are correlated with poor governance features at the level of the public pension funds.

The remainder of this paper is organized as follows. Section 2 describes our data and sample. Section 3 presents the empirical analysis of home bias. Section 4 relates home-bias to state-level corruption. Section 5 analyzes the costs of public pension fund home bias. Section 6 discusses and concludes.

\section{Data}

The bulk of institutional investment in private equity is made via distinct, legally separate, funds run by professional managers (referred to as the GPs), as the selection of appropriate direct investments requires resources and specialized human capital that few institutional investors have. PE funds are raised for a specified period (typically a 10-12 year, with possibility for shorter extensions) and are governed by partnership agreements between the investors and the fund's principals. The agreement specifies the nature of the fund's activities, the division of the proceeds, and so forth. Private equity groups typically raise a fund every few years.

To examine the investment patterns and investment performance of LPs, we construct a sample of PE fund investments by institutional investors over the period 1980-2009 using data obtained from four major sources: Thomson Reuters' Venture Economics (VE), Private Equity Intelligence (Preqin), VentureOne (V1) and Capital IQ (CIQ). None of the four data sources provides complete coverage of any given LP's investments, or of the LPs in any given fund, a drawback noted by Lerner, Schoar and Wongsunwai (2007), who use VE data in a related 
exercise, and Hochberg, Ljungqvist and Vissing-Jorgensen (2010), who employ similar data for VC funds to test an informational hold-up model. We obtain performance data for the funds, in the form of net IRRs and multiples of committed capital, and from Preqin. Data on the location, portfolio size and type of institutional investor, as well as information on the location of the PE funds are obtained from a combination of the above four sources.

One drawback of this type of data is that data on the size of the investment, i.e. the commitment by the LP to the fund, is generally incomplete. In our sample, the size of the commitment is available for roughly half of the observations. For public pensions, the coverage is roughly $80 \%$, whereas for the other LP types it is substantially below $50 \%$. In order to exploit the richness of the data on different types of investor classes, our headline use the full sample and treat the investments as all of equal size, effectively equal-weighting the investments. However, we show that the main results all go through for the LP categories with sufficient coverage, and are quantitatively quite similar if one focuses only on the smaller sample of investments for which the dollar value of the LP commitment is available. That is, we calculate overweighting as a share of total known commitments and value-weight all performance regressions by the size of the commitment, including only observations for which we actually have commitment data.

State-level corruption measures are obtained from Glaeser and Saks (2006). Glaeser and Saks (2006) derive corruption levels from the Justice Department's “Report to Congress on the Activities and Operations of the Public Integrity Section,” which lists the number of federal, state and local public officials convicted of a corruption-related crime by state. They divide these convictions by average state population from the 1999 and 2000 Census to obtain an estimate of the state corruption rate per capita. Alaska ranks as the most corrupt state in their ranking, followed by Mississippi, Louisiana and South Dakota. The least corrupt states in the GlaeserSaks ranking are Oregon, Washington, Vermont and Minnesota. We refer to the Glaeser-Saks measure as the GS measure.

Additional measures of state-level corruption are taken from the survey of state corruption by Boylan and Long (2003) as covered in the New York Times. The survey by Boylan and Long (henceforth BL), completed in 2003, asks state house reporters to assess state officials and rank their state in terms of corruption on a scale of 1 (clean) to 7 (crooked). In three states, correspondents chose not to respond to the survey. Both the BL survey ranking and the 
indicator for non-response to the BL survey correlate highly with the GS corruption rate levels.

We also use data on the public pension funds from a variety of sources. The data on whether a public pension fund represents teachers, public safety officials, both, or neither comes from the Center for Retirement Research (2006), augmented by additional collection based on the name of the pension fund. State level pension contributions and the number of covered workers are taken from the dataset of Novy-Marx and Rauh (2010). State revenues are from the Annual Survey of State Government Finances (U.S. Census Bureau (2009)).

As can be seen in Table 1, combining the four private equity data sources and retaining only observations with available location data gives us 18,828 investments by 631 unique LPs investing in 3,554 PE funds. ${ }^{10}$ The top panel of Table 1 shows the number of investments by source and investment type. Of these 18,828 observations, roughly 57 percent are present in Preqin only, 11 percent are present in both Preqin and VE/V1, 13 percent are present in both Preqin and Capital IQ, and 7 percent are present in all three datasets. Thus, Preqin alone would cover 89 percent of the investments in our sample. The remaining 11 percent of the sample is represented by roughly 2,210 observations, of which 1,024 are present in Capital IQ only, 380 are in VE/V1 only, and 806 are in both Capital IQ and VE/V1. Thus, Capital IQ alone would cover 29 percent of the observations in the sample, and VE/V1 alone would cover around 25 percent of the observations in the sample.

The bottom panel of Table 1 shows the investments sample broken down by type of PE fund. Thirty percent of the investments are buyout investments, 30 percent are VC investments, and 13 percent are real estate. The remaining 27 percent are other types of PE funds, including funds of funds, distressed debt, mezzanine, and natural resources investments. As noted, throughout this paper, we refer to investments in VC, buyout, real estate, and all other private fund type categories as private equity or PE investments.

Table 2 presents the number of investments by type of LP and by type of investment. Investments by public sector pension funds comprise 11,799 observations, or 63 percent of the sample. Investments by endowments and foundations each comprise 16 percent of the sample, and investments by private sector pension funds make up the remaining 6 percent. Of the public sector pension fund investments, 32 percent are in buyout, 26 percent in VC, 16 percent in real

\footnotetext{
${ }^{10}$ For comparison, in their analysis, Lerner, Schoar and Wongsunwai employ a dataset from VE alone comprised of 4618 investments in 838 funds by 352 LPs.
} 
estate and 26 percent in other. Private sector pension funds invest comparatively more in venture and buyout, and less in real estate and other categories.

As can be seen from the table, endowments have a heavier allocation to VC than either public or private pension funds, with $40 \%$ of endowment investments going towards this investment type. Compared to public pensions, endowments invest less in buyout (26 percent of investments versus 32 percent) and less in real estate (8 percent of investments compared to 16 percent). The heavy weighting on VC is particularly apparent in the endowments of private institutions, where over half of investments are in VC.

In contrast, the endowments of public institutions have allocations to VC that are much lower than the endowments of public institutions and much more like the public sector pension funds. However, public institution endowments have less buyout than any other category and more investments in the "other" category. Foundations resemble endowments to some extent, in that they have more VC investments than buyout investments, but they also have a larger share of investments in the other category than any other LP type. Endowments associated with public institutions have allocations to the different fund types that are closer to the allocations of public sector pension funds. Private institution endowments have more than half of investments in VC, whereas for public sector endowments, the investment is only 28 percent.

The "other" investments of public pension funds are approximately 25 percent in funds of funds. Public sector funds use a wide range of other investments. The other category for public pension funds contains 20 percent distressed debt, 14 percent mezzanine, and 10 percent natural resources. The other investments of private pension funds are also only about 25 percent in funds of funds, with 26 percent of the "other" investments in balanced funds and the rest distributed across a number of other categories including distressed debt and mezzanine. The large allocation of public institutions to other is 40 percent in funds of funds investments, 19 percent in distressed debt, and 16 percent in natural resources. The distribution within the "other” category for foundations is quite similar to that of the public endowments.

Table 3 presents additional summary statistics for our sample. Panels A presents summary statistics for the net IRR returned by funds invested in broken out by institutional investor type, for the 14,881 observations for which we have performance data. Funds invested in by endowments return a mean (median) net IRR of 12.01\% (6.10\%), and those invested in by foundations return $9.78 \%$ (6.30\%). PE funds invested in by private sector pension funds return a 
mean (median) IRR of $8.41 \%$ (6.45\%), while those invested in by public sector pension funds return a mean (median) IRR of 5.78\% (5.00\%).

Panel B of Table 3 presents summary statistics for an alternative performance measure, the multiple of committed capital returned by PE funds, again broken out by institutional investor type. Funds invested in by endowments return a mean multiple of 1.79x, while those invested in by foundations return a mean multiple of 1.66x. PE funds invested in by private sector pension funds return a mean multiple of $1.57 \mathrm{x}$, while those invested in by public sector pension funds return a mean multiple of $1.36 x$.

Panel C of Table 3 breaks out our sample by type of institutional investor and PE fund vintage year. Consistent with the growth of the PE sector since the 1980s, the bulk of our sample observations are investments by LPs in funds from vintage years in the 1990s (5,519 investments) or 2000s (12,557 investments), with a smaller proportion of investments made during the 1980s. ${ }^{11}$ Public pension fund investments represent the largest portion of our sample (11,797 investments), followed by endowments (2,958 investments) and foundations (2,953 investments).

Panel D of Table 3 presents summary statistics for the size of the institutional investor's portfolio at the end of our sample period, 2009. Pension funds, both private and public sector, have the largest portfolio sizes on average, at \$1186 million and \$1176 million, respectively.

Finally, Panel E of Table 3 presents summary statistics for state-level variable used in our analysis. The mean state in our sample (excluding WY due to lack of WY LPs in our sample and excluding DC for the Glaeser-Saks data) has a GS corruption index level of 0.28, a NYT survey corruption score of 3.22, and a non-response to NYT survey rate of 0.08 . The mean state has a population of 6,129,246, where the populations are measured as of 2009. Growth in nominal GSP is measured by year from 1980-2009.

Appendix Table 1 presents the geographical distribution of our sample investments, by the state where the fund is headquartered. Perhaps unsurprisingly, given that we focus on the broad category of PE funds, the highest proportion of our sample investments are in funds headquartered in CA (25.84\%), followed by NY (23.37\%) and MA (16.9\%). Nine states have no PE funds in which investments were made in our sample (AK, HI, KS, MS, MT, ND, NV, SD

\footnotetext{
${ }^{11}$ In untabulated results, we find that the results on both overweighting and underperformance are very consistent across time periods of the sample.
} 
and WV) and hence are not shown.

In columns (2) and (3) of Appendix Table 1, we separate investments into those made by in-state LPs and those made by out-of-state LPs. 15,678 of the 18,828 investments in our sample are made by LPs who are not located in the same state as the fund they are investing in. The remaining 3,150 investments are made by LPs from the same state as the fund they are investing in. We call investments made by LPs from the same state as the fund they are investing in instate investments. Of the 3,150 in-state investments, 37.87\% of them are California investments, 17.37\% are New York investments, and 12.89\% are Massachusetts investments. These percentages reflect both the extent of LP private equity portfolios in the state and the tendency of these LPs to invest within the state. Appendix Table 2 shows analogous calculations weighted by committed capital for observations which committed capital is available.

\section{Empirical Analysis of Overweighting and Performance}

We begin our analysis by examining the overweighting of LPs with respect to their local geography and pooled across time. We quantify this overweighting by type of LP, finding a particularly strong effect among public pension funds, as compared to private sector pension funds, endowments, and foundations. We also examine how this effect varies among different types of investment: buyout, venture, real estate, and other. We then examine performance differences between in-state and out-of-state investments for different types of LPs and funds.

\section{A. Overweighting of In-State PE Investments: Analysis Pooled Over Time}

There are several possible benchmarks for the share of an LP's PE investments that would be expected to be in-state if there were no home state overweighting. In this paper, we focus on two benchmarks. The first is the share of all investments that are in the state in question. Consider, for example, Minnesota, a state chosen at random. Appendix Table 1 shows that across all investments in our sample, $0.79 \%$ are investments in funds that are located in Minnesota. The first benchmark thus would imply that if Minnesota LP investors behave like the average LP investor around the country, only $0.79 \%$ of their portfolio over the sample period would be expected to be in funds located in Minnesota. We call this benchmark the overall state share. 
The drawback of the overall state share is that it will be biased upwards if the state itself overweights local investments, and it will be biased downwards if the other states that invest in the state particularly overweight their own local investments. To see this, suppose that all the states investing in Minnesota had a 10\% overweighting of their own funds. Then the Minnesota share of those other states should really be divided by 0.9 to reflect the expected portfolio without home bias.

The second benchmark we consider is therefore the share of all non in-state investments that are investments in the state in question. Appendix Table 1 shows that excluding in-state investments, $0.68 \%$ of the PE investments in the sample are in Minnesota. The second benchmark would imply, therefore, that if Minnesota LP investors had the same geographical investment distribution as the average LP investor does in its out-of-state investments over the course of the sample period, only $0.68 \%$ of their pooled portfolio over the sample period should be in Minnesota funds. We call this benchmark the state's share of all out-of-state investments.

We first examine in-state overweighting by LPs, pooling the investment sample across time. Column (1) of Table 4 presents the equal-weighted investment share by LPs. In contrast to Appendix Tables 1 and 2, which lists investment shares by state of the investment (GP), the state listed in Table 4 is the state of the LP investor. Column (2) of Table 4 shows the in-state bias relative to the first benchmark, the overall state share, based on the pooled sample. For example, for California, this in-state bias is 9.3\%, calculated as the $35.1 \%$ in-state share of California LPs minus the $25.8 \%$ share of the PE market that California GPs have nationwide over the sample period from Appendix Table 1. Column (3) shows the pooled in-state bias relative to the second benchmark, the state's share of all out-of-state investments. Here the figure for California is $11.7 \%$, which is the $35.1 \%$ in-state share of California LPs minus the $23.4 \%$ share of California GPs in the total number of investments by LPs outside of California.

Consider Minnesota as a further example. If Minnesota LP portfolios employed the same geographical investment distribution as the LP average across the country over the course of the sample, they would be expected to invest $0.8 \%$ of their pooled portfolio in Minnesota investments. If Minnesota LP portfolios employed the same geographical investment distribution as the LP average across the country for out-of-state investments only, they would be expected to invest $0.7 \%$ of the portfolio in Minnesota investments. In fact, since Minnesota invests $9.7 \%$ of the PE portfolio in Minnesota funds, they have an overweighting of $8.9 \%$ of the portfolio (=9.7\% 
- $0.8 \%$ ) relative to the overall state share (the first benchmark) and $9.0 \%$ of the portfolio ( $=9.7 \%$ - 0.7\%) relative to the state's share of out-of-state investments (the second benchmark).

The state with the most overweighting in the pooled sample is Massachusetts. Over $40 \%$ of the PE investments of LPs located in Massachusetts are in Massachusetts-based PE funds. Massachusetts does have more PE investment opportunities than the average state of its size, but this is reflected in the fact that among all LPs in our sample, 16.9\% of PE investments are in Massachusetts and $17.7 \%$ of out-of-state investments are in Massachusetts. ${ }^{12}$ For Massachusetts LPs, however, $41.5 \%$ of the PE investments are in funds located in Massachusetts, corresponding to an overweighting of $24.6 \%$ of the portfolio relative to the overall state share and $23.8 \%$ of the portfolio relative to the state's share of all out-of-state investments.

After Massachusetts, states with the next largest home bias relative to the state's overall share are Ohio (18.2\%), Tennessee (12.5\%), Pennsylvania (11.5\%), Illinois (11.5\%), and Texas (11.4\%). Including Massachusetts, these are the six states with a local state overweighting of more than 10 percent of the portfolio, relative to the state's overall share. On the second benchmark, the state's share of all out-of-state investments, the states with the next largest home bias after Massachusetts are Ohio (18.7\%), Tennessee (12.5\%), Pennsylvania (12.1\%), Illinois (11.7\%), California (11.7\%), and Texas (11.2\%). Including Massachusetts, these are the seven states with a local state overweighting of more than 10 percent of the portfolio, relative to the state's share of all out-of-state investments.

The right columns of Table 4 show a value-weighted version of the analysis for the subsample for which we have information on the size of the LP commitment. This panel table looks at the overweighting as a function of total known committed dollars, rather than of the total number of investments. We find broadly similar results. Overall, the average equal-weighted home-state bias is $3.80 \%$ and the average value-weighted home-state bias is $4.09 \%$ for the pooled sample.

\section{B. Overweighting of In-State PE Investments: 5-Year Rolling Benchmarks}

If geographical investment patterns change over time, it is useful to examine the home-

\footnotetext{
${ }^{12}$ The fact that the state's share of all out-of-state investments is larger than the state's overall share indicates that Massachusetts PE funds receives a particularly large share of their out-of-state investments from LPs with more substantial biases towards their own states.
} 
state overweighting on a rolling basis over the several years preceding any given vintage, as opposed to over the entire sample. Given the structure of the data and the nature of PE investments, we do this relative to the previous five years of investment activity.

Table 5 presents this analysis in analogous format to Table 4. Here the level of calculation is the [LP $x$ Vintage], where only [LP $x$ Vintage] observations for which there is a PE investment are included. For each [LP x Vintage], we calculate an excess share of home-state investments over the preceding five years, relative to both the overall state share during that time period and the state's share of out-of-state investments during that time period.

The results in Table 5 are qualitatively similar to, and in fact stronger, than those obtained in Table 4 when pooling the sample investments over time. Here, the state with the highest level of overweighting on an equal-weighted basis is Ohio, with a home bias that averages 32.4\% of its PE portfolio relative to the overall state share in each year and 33.1\% share relative to the state's share of all out-of-state investments (both based on the preceding five years of investment). After Ohio, the states with the largest home bias based on the rolling five year benchmark are Massachusetts (31.7\% versus overall state share, 31.0\% versus share of out-ofstate investments), Illinois (22.3\%, 22.7\%), Tennessee (18.9\%, 18.9\%), Pennsylvania (16.0\%, 16.7\%), California (13.2\%, 15.2\%), Minnesota (13.3\%, 13.5\%) and Texas (13.1\%, 13.0\%). In all, there are eleven states with a local state overweighting that averages more than $10 \%$ of their PE portfolio on a rolling five year basis.

Analogous to Table 4, the right-hand columns of Table 5 present a value-weighted version of the analysis for the subsample for which we have information on the size of the LP commitment to the fund. Here, we compute overweighting as a function of the total known committed dollars, rather than total number of investments. As was the case for the sample pooled over time, we again find broadly similar results to the equal-weighted analysis, with the average equal-weighted home-state bias at $6.85 \%$ and the average value-weighted home-state bias at $7.17 \%$.

The next logical question is the extent to which the in-state overweighting is concentrated in certain types of LPs, and whether it is concentrated in certain types of investments. Table 6 addresses this question.

The first row of Table 6 shows the mean and standard error of the mean for the in-state 
investment indicator over all 18,828 observations in the full sample. The second row of Table 6 shows the same statistics for the 18,102 observations for which funds exist in the state of the LP. That is, this sample excludes investments by LPs in states for which there were no PE funds that any LP in the sample invested in (AK, HI, KS, MS, MT, ND, NV, SD and WV). The next two sets of columns present the excess in-state LP portfolio weighting versus both benchmarks: the overall state share and the share of out-of-state investments, calculated for each LP in each vintage year based on investments in the preceding 5 year period, and averaged over the sample. We observe that here there is a 7.8 percentage point overweighting relative to the overall state share, and an 8.1 percentage point overweighting relative to the state's share of all out-of-state investments, both statistically significant at the $1 \%$ level.

The next panel of Table 6 shows means and associated standard errors by LP type for the in-state share and the differences between the in-state investment share and the two benchmarks, along with t-tests of statistical significance. Public pension funds overweight in-state investments by 9.2 to 9.7 percentage points on average. Endowments overweight in-state investments by 6.7 percentage points on average. Private sector pension funds overweight in-state investments by 6.2 to 6.5 percentage points on average. Foundations overweight in-state investments by 3.7 to 3.8 percentage points on average. The final column of Table 6 shows a statistical test of whether each LP type is statistically different from the public pensions, and indeed we see that there is a statistically significant difference of 3 to 6 percentage points between public pension LPs and other LPs when it comes to this local overweighting.

The next sets of statistics in Tables 6 show the means, standard errors, differences, and statistical tests by the type of investment (buyout, venture, real estate, or other), and also within each investment type by the type of LP investor. Public pensions display a 5.3 to 5.8 percentage point home-state overweighting in buyout, a 15 to 15.4 percentage point home-state overweighting in venture capital, a 14.9 to 15.6 percentage point home-state overweighting in real estate, and a 7.2 to 7.8 percentage point home-state overweighting in the other types of investments. It thus appears that public pension funds most overweight in-state venture investments and real estate investments, with in-state investments in the "other” category and in buyout overweighted to a lesser extent.

Within these investment types, there are generally significant differences between the extent of public pension overweighting of in-state investments and the extent of overweighting 
by other types of LPs. In venture capital, the 15.4 percentage point public pension overweighting (using the second benchmark) is 10.5 percentage points greater than the overweighting seen in private pensions, 6.6 percentage points greater than the overweighting seen in endowments, and 8.5 percentage points greater than the overweighting seen in foundations. Private pensions, endowments, and foundations do still overweight venture capital, but not to nearly as large an extent as public pension funds. A similar statement holds for real estate, although private pension funds are closer to public pension fund LPs in this category.

In buyout, the in-state overweighting by public pension LPs is no greater than the in-state overweighting of other types of LP investors. In all cases except foundations, the overweighting of in-state buyout relative to out-of-state investments is around 5-6 percentage points. For foundations it is around 3 percentage points but there is not a statistically significant difference with public pension LPs. In the "other" category of investments, it appears that public and private pension LPs do the most in-state overweighting with, with foundations doing significantly less.

Overall, Table 6 presents a clear picture of substantial overweighting of in-state investments, particularly by public pension funds investing in venture capital and real estate, but also across the board for other LP types and investment types. In Table 7, we perform similarminded tests in regression form; we perform panel regressions in which the dependent variable is the LP's excess share of in-state investments over the previous five years, relative to the benchmark representing the share of investments in the state by out-of-state LP's over the preceding five year period. The observation is an LP-year. The independent variables are the natural logarithm of the size the LP's private equity portfolio in dollar terms, the natural logarithm of the state population, the growth in nominal gross state product (GSP), and indicator variables for LP type (the omitted category is foundations). Standard errors are clustered at the LP-state level, and all models include vintage year fixed effects.

Looking at the estimates from the regression models in Table 7, we observe similar patterns to those documented in Table 6. The coefficient on the public pension fund indicator is positive and significant, with a magnitude that ranges from 12.2 to 13.1 percent, with no significance on the coefficients for other types of investors, suggesting that endowments and private pensions do not differ significantly from foundations in their in-state overweighting. For the control variables, we observe a significant negative relationship between the size of the LP's 
PE portfolio and the extent to which it overweights investments in its home state, and a significant and positive relationship between home state population and overweighting.

\section{Underperformance of In-State Investments}

We next ask how in-state investments perform relative to out-of-state investments. One possibility is that public pension funds are able to make use of local connections, networks and political access to gain better information than out-of-state investors on the prospects of funds located in their home-states or to gain access to more and better funds in their home-states. If so, we would expect the in-state investments made by local public pension funds to perform better than the investments made in their home-state by out-of-state investors who lack such access; we may even observe that the in-state investments made by local public pension funds to perform better than the investments made by these same pension fund managers in out-of-state funds. Indeed, Coval and Moskowitz (2001) find that U.S. mutual fund managers of public equities earn substantial abnormal positive returns in their local investments in public equities, due to informational advantages. Such informational advantages might be expected to be particularly strong in the realm of private equity, an investment setting characterized by substantial asymmetric information.

Table 8 shows t-tests of differences in net IRR between in-state and out-of-state investments. The left panel analyzes the raw IRR, the middle panel examines the IRR minus the mean of all other observations in the same state and vintage year of the investment fund (the GP), and the right panel examines the IRR minus the mean of all other observations in the same state, vintage and investment type of the investment fund (i.e. buyout, venture capital, etc.). Controlling in this fashion for the state, vintage year and type of the fund is analogous to including a fixed effect for these factors. This is important as expected return and risk may vary over time, by state, and by the type of investment.

Each set of three rows consists of a row of means, a row of standard deviations, and a third row with observation counts and t-statistics. The t-statistic is for the test with null hypothesis that the difference between the out-of-state IRRs and the in-state IRRs equals zero. The first three rows consider all observations, the next set of three rows considers only public pensions, the next set of rows considers only private pensions, and so forth. 
The left side of the top panel of the table shows that in terms of raw IRR, out-of-state investments outperform in-state investments by 2.73 percentage points, and that the difference is statistically significant with a t-statistic of 4.11 . The middle of the top panel of the table examines the same comparison but with respect to the IRR minus the mean of all other investments in the same state and vintage. This is analogous to a regression with state-by-vintage fixed effects, and tests whether LPs actually do worse when investing in their home state than other investors do when investing in the same state. Here, out-of-state investments outperform in-state investments by 2.87 percentage points, and the difference is statistically significant with a t-statistic of 5.38. We can further adjust for the investment type of the fund in question, to test whether LPs actually do worse when investing in their home state than other investors do when investing in the same state, in the same vintage year, and in the same type of fund. We do so in the right-most columns of the table. Here, out-of-state state investments outperform in-state investments by 2.02 percentage points, and the difference is statistically significant with a tstatistic of 4.63. So it seems clear that overall, out-of-state investments outperform in-state investments. Appendix Table 3 provides value-weighted versions of this analysis, with very similar results. ${ }^{13}$

This pattern appears particularly strongly among investments for which the LP was a public pension fund. The second set of three rows shows that the difference in average raw IRR is 2.78 percentage points, the difference in average IRR demeaned by state and vintage is 3.75 percentage points, and the difference in average IRR demeaned by state, vintage and type is 2.60 percentage points. Thus, we observe a 2.5-4 percentage point underperformance of in-state investments by public pension LPs. Similar magnitudes are found in the value-weighted results in Appendix Table 3.

The panels below the top three investigate this relationship for other LP types. When examining raw net IRR, there is at best very weak evidence that there is any underperformance of in-state investments. While the direction of the sign is usually the same (in-state investments perform worse than out-of-state investments), the magnitudes are smaller and the t-statistics are very weak. Public endowments are the closest to showing some underperformance of in-state

\footnotetext{
${ }^{13}$ In particular, in Appendix Table 3 we look at the underperformance of in-state investments where the means are weighted by the size of the LP commitment. For some LP types, including private pensions and private endowments the joint coverage of net IRR and LP commitment size do result in very small sample sizes.
} 
investments, though the t-statistic is only 1.30. When the investments are demeaned by state and vintage or state, vintage and investment type, however, any underperformance by non-public pension LPs is even less apparent. Although not statistically significant, the level of the difference is even occasionally negative for public endowments and foundations. Figure 1 depicts these performance differences in terms of net IRR minus the state-vintage mean, Figure 2 in terms of net IRR minus the state-vintage-type mean. Untabulated estimates indicate that even considering all LPs who are not public pension funds together, there is still no significant performance effect of in-state investments.

In sum, Figures 1 and 2 demonstrate that only public pension LPs achieve systematically worse performance when investing in their home states, even controlling for the possibility that investments in those states just performed poorly overall. Public pension LPs actually do worse when investing in their home state than other investors do when investing in the same state, year, and investment type.

Figure 3 repeats a similar analysis to Figure 1, but for the multiple of invested capital instead of the net IRR. The conclusion is the same as in Figure 1. Public pension LPs achieve lower multiples of invested capital when investing in their home state than other investors do when investing in the same state. Public university endowments are the only other group where the underperformance would be of an economically significant magnitude, but the difference is not at all statistically significant.

Figure 4 shows the relative performance of public pension PE investments in-state versus out-of-state by investment type category, with a t-statistic for whether the performance is equal. Performance is measured as net IRR minus the mean of all other investments in the same vintage and GP state. The figure shows that the underperformance is statistically significant across all categories. The magnitude of the underperformance is greatest for venture capital, where the difference between in-state and out-of-state investments is 3.4 percentage points. But there is clear underperformance of in-state versus out-of-state investments across all the categories.

Table 8 and Figures 1-4 indicate that in-state investments by public pension LPs underperform the benchmarks. The next set of results examines these results in a regression context with clustered standard errors and allowing for control variables. The first and fourth columns of Table 9 (Panel A) present regression versions of the results in Table 8. The observation is an investment by an LP in a fund, and standard errors are clustered at the level of 
the LP state. The dependent variable in the first set of columns is the net IRR minus the mean net IRR for all investments made in the same state in the same vintage year, and in the second set of columns is the net IRR minus the mean net IRR for all investments made in the same state in the same vintage year of the same investment type. The estimates in the first and fourth columns of Table 9 confirm that in-state investments underperform out-of-state investments by 3.75 net IRR points in excess of the mean state-vintage net IRR, and by 2.62 net IRR points in excess of the mean state-vintage-type net IRR. These are precisely the results found in Table 8.

An alternative hypothesis for the observed performance differential is that public pension fund LPs are willing to accept lower returns on home-state investments relative to out-of-state investments due to greater perceived uncertainty about the quality of investment funds or prospects in other states. It is unclear why this argument would apply solely to public pension funds and not to other types of institutional investors. Nevertheless, if this argument is valid, one would expect that LPs would have greater uncertainty regarding the prospects of more distant states than immediately neighboring states; and thus, that we should observe LPs significantly overweighting neighboring states (relative to non-neighboring states) and achieving lower performance on their investments in neighboring states relative to their performance on investments in non-neighboring states.

In the second and fifth columns of Table 9, we include an indicator variable for whether the investment in question was made by the LP in an immediately neighboring state. As can be seen from the table, we observe no economically or statistically significant difference between public pension fund performance on out-of-state investments made in neighboring states versus performance on those out-of-state investments made in non-neighboring states. The coefficients on the in-state indicator are virtually unchanged from those in the previous columns.

Furthermore, in untabulated analysis, we find little evidence of overweighting of neighboring states in LP portfolios. ${ }^{14}$

Additionally, we note that precise measures of risk for our PE fund investment sample are not available, and thus, that differences in returns may in theory be due to differences in risk profiles of investments even within type, state and vintage year. That said, there is little reason to believe that such effects would materialize only in the investments made by public pension

\footnotetext{
${ }^{14}$ Specifically, when we examine the weighting of neighboring state investments relative to the second benchmark, we find that neighboring state investment averages $9.9 \%$ of all investments relative to a benchmark of $9.2 \%$.
} 
funds. ${ }^{15}$

The third and sixth columns of Table 9 add the excess LP in-state share as well as an interaction between the in-state indicator and the excess in-state share. The excess LP in-state share is defined as the difference between the LP's in-state share and the predicted in-state share based on the state's share of all investments that are not in-state investments (the second benchmark). The third and sixth columns of Table 9 shows that for each 10 percentage points of excess in-state share, the net IRR is 6.8 percentage points worse when adjusting net IRR by the state-vintage mean, and 4.2 percentage points worse when adjusting net IRR by the stat-vintagetype mean. Thus, public sector pension funds who overweight in-state more also appear to be associated with worse investment performance overall. ${ }^{16}$

Panel B repeats the analysis in Panel A, substituting multiple of invested capital as the performance measure. While we continue to observe that investments made in-state by the public pension fund LP have lower performance, we also observe no significant relationship between the excess LP in-state share and the performance of the investment in terms of adjusted multiple of invested capital.

In sum, public pension funds' own-state investments perform significantly worse than their out-of-state investments, by roughly 3-4 percentage points of net IRR per year, and those that that overweight their portfolios towards home-state investments appear to perform proportionally worse on their PE investments overall. Among out-of-state investments, there is no difference between the performance of investments in neighboring states and the performance of investments in non-neighboring states.

\section{Why Do Public Pension LPs Overweight Local Investments?}

\footnotetext{
${ }^{15}$ In untabulated results, we attempt to evaluate the correlation between the riskiness of the PE investments and their in- or out-of state status. Specifically, as an admittedly crude proxy, we calculate the within GP standard deviation of returns (net of state-by-vintage-by-type mean) across funds (for GPs who have raised at least 3 funds). We assign this GP-level risk measure to each investment made in a fund raised by that GP, and compute the correlation between the riskiness of each investment and its in- or out-of-state status. We find a negligible (-0.0018) correlation between the measure of riskiness of the investment and whether the investment is located in-state or out-of-state. We thank Jules von Binsbergen for this suggestion.

16 These results are robust to further controlling for the PE fund (GP) size and size squared in all performance regressions. As the size of the fund chosen also reflects the choice of the particular investment of the GP within the investment type categories, we present our headline results without these controls.
} 
Why do public pension funds overweight home-state investments with poor performance? Home-state investments are often justified in the context of Economically Targeted Investment (ETI) programs, so a natural hypothesis is that public pension systems are subject to political pressures to invest in their home state. These pressures may be higher in states where self-dealing, corruption and quid pro quo activity is more commonplace. To explore this hypothesis, we examine how commonly accepted measures of state-level corruption--as a proxy for political pressure--correlate with the public pension fund LP's decision to overweight local investments and also their performance in those investments. ${ }^{17}$ According to Glaeser and Saks (2003), state-level corruption is higher in less-educated and poorer states and in states with greater income inequality, and is unrelated to the size of state government. Thus, the GS corruption measures may also capture elements related to the sophistication of the managers of the state's public pension funds.

Table 10 relates the excess share of in-state investments by LP (using the second benchmark with a 5-year rolling average) to LP and state-level variables, such as the size of the LP's PE portfolio, whether it is a teachers' or public safety retirement fund, and the population of the state, as well as to the various state-level corruption measures: The GS corruption rate, the BL corruption survey, and an indicator for BL survey non-response. The upper panel of the table relates excess share of in-state investments for public pension funds only to the independent variables; the lower panel presents similar regressions for endowments as a whole, public institution endowments, private institution endowments, private pensions and foundations.

In the upper panel, we begin by relating the excess share of in-state investments to the corruption rate (column (1)). Column (2) adds a control for the size of the LP's portfolio, and column (3) adds a control for the state population). In column (4), we replace the GS corruption index with the BL survey measure and non-response indicator. In column (5), we include all three corruption measures (GS, BL, and BL non-response) as well as portfolio size, state population and indicators for whether the public pension fund represents teachers or public safety.

\footnotetext{
${ }^{17}$ In unreported results we also examined governance structure at the pension fund level, including the extent of elected versus political appointees on the fund boards. We did not observe any strong patterns in the data with respect to local overweighting and performance. We note that every public pension fund LP in our sample has at least one board member appointed by the state governor. The regressions presented in this paper are robust to the inclusion of fund-level board governance variables as controls.
} 
Looking at the models in the panel, it is clear that for public pension funds, higher statelevel corruption is positively correlated with the excess share of in-state investments. The coefficient on the corruption index is significant in all models, both economically and statistically: a one standard-deviation increase in the corruption index (0.14) implies an increase in the excess share of in-state investments of 7-8 percentage points. When we include only the BL survey measures, both BL survey and the non-response indicator enter significantly. When both the GS index and the BL measures are included, the GS measure is significant at the 1\% level; the BL survey non-response indicator remains statistically significant but not the BL index itself. The explanatory power of the models appears to be moderate, with the $\mathrm{R}^{2}$ of the most comprehensive regression model (column (5)) at 0.20 , most of which comes from the corruption measures. These results are consistent with recent allegations of pay-to-play schemes involving political pressure on public pension fund managers in states including Illinois and New York.

In contrast, the lower panel of the table suggests that very different forces are at play for other types of institutional investors. In column (1) of the lower panel, we see that corruption is negatively and significantly related to the excess share of in-state investments for endowments, albeit at a 10\% significance level. This effect is larger when we isolate to private institution endowments alone (column (3)) and positive but insignificant for public institution endowments, private pensions and foundations.

How then does corruption relate to the performance of in-state investments? In Table 11, we regress the performance of an investment on an indicator variable for whether it is an in-state investment, the corruption index, the size the LP's PE portfolio, and interactions between in-state and corruption, in-state and portfolio size, and portfolio size and corruption. In columns (1) and (2), we isolate out models to investments made by public pension funds; in columns (3) and (4) we isolate to investments made only by other types of LPs. In Panel A, the dependent performance variable is the net IRR minus the vintage year mean net IRR for investments in that state; in Panel B, it is the multiple of invested capital minus the vintage year mean multiple for investments in that state.

Looking at Panel A, we see little significant relationship between corruption and the performance of in-state investments. While the most parsimonious specification (column (1)) exhibits a weakly significant positive coefficient on the corruption index, suggesting a possible relationship between state-level corruption and the performance of the public pension LP's 
investments, this loses significance in the expanded model in column (2). The results in Panel B are stronger. Here, in the expanded model (column (2), we see a significant positive relationship between the level of the corruption index and the public pension LP's investment performance; we also observe a positive and significant coefficient on the interaction of the corruption index with the in-state investment indicator, suggesting that in-state investments made by LPs in states with higher levels of corruption return higher multiples of investment capital (though not higher IRRs).

In looking at public equity investments by state pension funds, Brown et al (2011) find that state pension funds in more corrupt states overweight their investments in the stock of local companies more than those in less corrupt states, and that the difference in performance between in-state and out-of-state stock investments is strongest for the state pension plans located in more corrupt states. While the in-state public equity investments in Brown et al (2011) outperform outof-state investments by the 20 state pension funds they examine, this is in clear contrast to the underperformance of in-state private equity investments by public pension funds that we document, though the direction of the relationship between corruption and performance is positive in both cases. The contrast between the performance patterns and overweighting patterns both from our analysis and the analysis in Brown et al (2011) suggests that the relationship between governance both investment allocations and performance likely warrants further analysis than is possible using the data available to us.

\section{Cost of In-State Overweighting and Underperformance by Public Funds}

We now turn to examining how much in-state overweighting and underperformance costs the state public pension systems in the study. In Table 12, we show unadjusted public pension fund home-state weighting and performance statistics pooled across years. The first column shows the public pension LPs' in-state share and the second shows the state's share of all out-of-state investments by public pension fund LPs. As an example, consider the state of Massachusetts, one of the highest overweighting states in the sample. In the pooled sample period, $44.2 \%$ of Massachusetts public pension PE investments are in the state, while 13.7\% of all investments by non-Massachusetts LPs are in Massachusetts. The middle panel then shows the net IRR for three types of investments: (i) LP and GP both in the state; (ii) LP not in the state, GP in the state; (iii) 
LP in the state, GP not in the state. Keeping with our example, in Massachusetts: (i) the average net IRR for investments where both the public pension LP and GP are in Massachusetts is 2.24\%; (ii) the average net IRR when non-Massachusetts public pension LPs invest in Massachusetts is $11.33 \%$; and (iii) the average net IRR when Massachusetts public pension LPs invest outside of Massachusetts is $10.86 \%$.

Overall, Table 12 shows that the average LP(in)GP(in) investment returns $0.44 \%$ in terms of net IRR, the average LP(out)GP(in) investment returns 3.99\%, and the average LP(in)GP(out) investment returns $5.98 \%$. Thus, in the raw data, the in-state private equity investments by public pension LPs yield 5.5 percentage points lower returns annually than their out-of-state investments. In other words, the net IRR difference due to overweighting in-state investments, assuming that the public pension fund could have achieved the realized returns on their out-ofstate investments with this money if it had been invested out of state, costs $5.5 \%$ annually in net IRR on average.

Table 13 builds on Table 12 by calculating the 5-year rolling benchmarks for the in-state share, instead of the shares pooled over time that were shown in Table 12. The first two columns therefore are a breakdown similar to Table 5 but using only public pensions. This calculation only measures overweighting relative to the preceding five years of investment history, rather than the entire sample.

The middle three columns of Table 13 again show the net IRR for the same three types of investments as in Table 12, but now relative to the vintage mean. This calculation therefore benchmarks the performance not to the average of the entire sample of similar geographical investments but rather to the average of similar geographical investments within the same vintage. LPs that engage in poor market timing therefore do not appear to underperform as much on these measures. Still, in-state public pension investments underperform. The average LP(in)GP(in) investment returns $-2.33 \%$ in terms of net IRR net of the vintage mean, the average LP(out)GP(in) investment returns $-0.19 \%$ relative to the vintage mean, and the average LP(in)GP(out) investment returns $-0.67 \%$ relative to the vintage mean.

Table 14 shows the financial effects of overweighting and underperformance for public pension funds based on the 5-year rolling weight benchmarks and net IRR relative to vintage means from Table 13. The left panel uses the investments by out-of-state LPs in the state as a benchmark, and the right panel uses the investments by state LPs outside of the state as a 
benchmark. Predicted and excess shares are based on the 5-year rolling benchmarks shown in Table 13. The first column is therefore the IRR difference between home-state investments and investments by out-of-state LPs in the state, times the predicted in-state share. The second column is the IRR difference between home-state investments and investments by out-of-state LPs in the state, multiplied by the excess in-state share. The third column is the sum of the first two columns. The right panel presents the analogous calculations for the benchmark of state LP investments outside of the state.

Table 14 shows that if each public pension LP had performed as well on its in-state investments as out-of-state public pension LPs performed on investments in the same state, the public pension LPs would have reaped $\$ 1.23$ billion annually in additional returns. However, as was seen in Table 9, public pension funds that overweight in-state PE also tend to perform somewhat more poorly than other public pension funds when investing out of state. That is, they tend to be slightly worse investors overall. As a result, if each public pension LP were to have performed as well (and only as well) on its in-state investments as it did out of state, then the total annual benefit would only be $\$ 0.92$ billion.

A rather substantial share of these costs (on an aggregate dollar basis) come from a small number of states. California and Massachusetts comprise over $\$ 1$ billion of the $\$ 1.23$ billion annual cost in the left panel, and New York an additional \$0.2 million. Several states, including Colorado, Florida, North Carolina, and Pennsylvania, show no underperformance in-state versus out-of-state. New York has the interesting feature that its public pension funds' out-of-state performance is even worse than its in-state performance. If the benchmark is how New York public pension funds perform out-of-state, New York appears to benefit from home-state investing, even though it performs considerable worse on home-state investments than out-ofstate public pension LPs perform in New York.

Table 15 shows that despite the concentration of aggregate dollar costs in several states, a number of states nonetheless incur negative costs from investing that are a non-trivial share of either PE assets under management or as a share of annual contributions to the state's public pension funds. While California and Massachusetts still stand out, other states such as Connecticut, Illinois, Maryland, Tennessee, and Texas spend about 1\% of contributions each year on the loss from performing worse on in-state investments then they would if they invested out of state. 
Note that the differences in net IRRs between Tables 12 and 13 suggests that in many cases these costs would be substantially higher if performance were not adjusted for the average performance of investments of the same vintage. Indeed, some of the most negative average net IRRs appear to have come during vintages where PE overall performed poorly.

A caveat to the cost analysis presented here is that, given the incomplete data on actual dollar value allocations to funds, we must necessarily make some assumptions about the relative portion of the portfolio dedicated to any individual fund in our sample. Thus, for the purpose of providing a cost estimate, the calculations in Tables 12 through 15 assume that all fund investments are of equal size.

As an alternative, we have performed value-weighted cost analysis using only the investments for which commitment levels are available, and then extrapolating to the rest of the PE portfolio. The results are robust to considering the relative size of investments in this way. For most public pension funds there are commitment data on $80-90 \%$ of the in-state investments for which net IRR is also available. But some states, such as New York, hardly disclose commitment levels at all. In New York in particular, the commitment data are only disclosed on around $14 \%$ of the in-state investments for which net IRR is also available, and those investments performed much more poorly than the average New York investment for which the commitment is not available. Due to this problem, the total costs appear to be higher using the value-weighted cost analysis, on the order of over \$2.0-\$2.2 billion per year as compared to \$0.9-1.3 billion.

Given that the selection in disclosure of commitment levels seems to favor the worseperforming investments, we believe that the equal-weighted analysis provides a more accurate picture of the costs. Given the overall similarity of the picture using the value-weighted analysis, it is clear that the equal-weighted results are not being driven by small investments and are robust to considerations of investment size.

\section{Conclusion}

Investment biases by individual investors have attracted much scrutiny. Our knowledge of the biases and tendencies of institutional investors, in contrast, is more limited. In this paper, we examine the allocations and investment choices of institutional investors in the PE market and 
explore their tendencies to invest in their own state.

In contrast to the literature on home bias in mutual funds, our findings that public pension LPs underperform on local investments--and particularly so when they overweight those local investments--show that in the setting of PE investments by local public pension LPs, any informational advantages are overwhelmed by factors that induce local public pension LPs to select investments that ultimately perform worse. Our results suggest that the home-state overweighting by public pensions may be related to state-level corruption levels, suggesting political pressures or dealing may be related to the tendency to invest disproportional amounts in local funds. Further exploration of the governance channel is thus warranted.

These findings can potentially shed light on some of the previously documented puzzles in the private equity market (see, e.g., Lerner, Schoar and Wongsunwai (2007). Our work also opens interesting questions and avenues for future research. First and foremost, a caveat to our analysis is that we cannot assess the overall welfare impact of the home bias behavior we document for public pension funds. Further research that analyzes whether there are any potentially positive effects of local private equity investments on overall welfare would be useful. A second question is whether the patterns we document for private equity investments also generalize to other categories of investment, such as hedge funds, real assets, and outside public equity managers. Finally, future research should aim to develop a greater understanding of the overall role of private equity investments in the portfolios of different types of institutional investors. 


\section{References}

Baik, Bok, Jun-Koo Kang, and Jin-Mo Kim, 2010, “Local Institutional Investors, Information Asymmetries, and Equity Returns,” Journal of Financial Economics 97(1), 81-106.

Boylan, Richard, and Cheryl X. Long, 2003, "Measuring Public Corruption in the American States: A Survey of State House Reporters,” State Politics and Policy Quarterly 3(4), 420-438.

Brown, Jeffrey, Joshua Pollet, and Scott Weisbenner, 2011, “The Investment Behavior of State Pension Plans,” University of Illinois Working Paper.

Center for Retirement Research, 2006. State and Local Pension Data.

http://crr.bc.edu/images/stories/Frequently_Requested_Data/crr_state_and_local_pension_data.xls

Coronado, Julia L., Eric M. Engen, and Brian Knight, 2003. Public Funds and Private Capital Markets:

The Investment Practices and Performance of State and Local Pension Funds. National Tax Journal 56(3), 579-594

Coval, Joshua and Tobias Moskowitz, 1999. Home Bias at Home: Local Equity Preference in Domestic Portfolios. Journal of Finance 54(6), 2045-2073.

Coval, Joshua and Tobis Moskowitz, 2001. The Geography of Investment: Informed Trading and Asset Prices. Journal of Political Economy 109(4), 811-841.

Epstein, Larry G. amd Jianjun Miao, 2003. A Two-person Dynamic Equilibrium under Ambiguity. Journal of Economic Dynamics and Control 27, 1253-1288.

French, Kenneth R. and James M. Poterba, 1991. Investor Diversification and International Equity Markets. American Economic Review 81, 222-226.

Glaeser, Edward L. and Raven Saks, 2006. Corruption in America. Journal of Public Economics 90, 1053-1072.

Gompers, Paul, and Josh Lerner, 1996. The use of Covenants: An Analysis of Venture Partnership Agreements. Journal of Law and Economics 39, 463-498.

Gottschalg, O., and L. Phalippou, 2009. The Performance of Private Equity Funds. Review of Financial Studies 22, 1747-1776. 
Graham, John R., Campbell Harvey and Hai Huang, 2009. Investor Competence, Trading Frequency, and Home Bias. Management Science 55, 1094-1106.

Hochberg, Yael V., Alexander Ljungqvist and Annette Vissing-Jorgensen, 2010. Informational Hold-up and Performance Persistence in Venture Capital. Working paper, Northwestern University.

Hochberg, Yael V. and Tobias Muhlhofer, 2011. Market Timing and Investment Selection: Evidence from Real Estate Investors. Working paper, Northwestern University.

Jones, C., and M. Rhodes-Kropf, 2003. The Price of Diversifiable Risk in Venture Capital and Private Equity. Unpublished working paper, Columbia University.

Kaplan, Steven N., and Antoinette Schoar, 2005. Private Equity Performance: Returns, Persistence and Capital Flows. Journal of Finance 60, 1791-1823.

Korteweg, A., and M. Sorensen, 2010. Risk and Return Characteristics of Venture Capital-Backed Entrepreneurial Companies," Review of Financial Studies, forthcoming.

Lerner, Josh, and Antoinette Schoar, 2004. The Illiquidity Puzzle: Theory and Evidence from Private Equity. Journal of Financial Economics 72, 3-40.

Lerner, Josh, Antoinette Schoar and Wan Wongsunwai, 2007. Smart Institutions, Foolish Choices: The Limited Partner Performance Puzzle. Journal of Finance 62, 731-764.

Ljungqvist, A., and M. Richardson, 2003. The Cash Flow, Return, and Risk Characteristics of Private Equity. NBER Working Paper No. 9454.

Marsh, Bill, 2008. Illinois is Trying. It Really Is. But the Most Corrupt State is Actually. New York Times, 13 December 2008. http://www.nytimes.com/2008/12/14/weekinreview/14marsh.html

Mitchell, Olivia and Ping-Lung Hsin, 1997. Public Sector Pension Governance and Performance. In Salvador Valdes Prieto, ed. The Economics of Pensions: Principles, Policies, and International Experience. Cambridge: Cambridge University Press, pp. 92-126

Novy-Marx, Robert, and Joshua Rauh, 2010. Public Pension Liabilities: How Big Are They and What Are They Worth? Journal of Finance, forthcoming.

Quigley, J., and S. Woodward, 2003. An Index for Venture Capital. Unpublished working paper, University of California, Berkeley. 
Sorenson, Olav and Toby E. Stuart, 2001. Syndication Networks and the Spatial Distribution of Venture Capital Investments. The American Journal of Sociology 106, 1546-1588.

Strong, Norman and Xinzhong Xu, 2003. Understanding the Equity Home-Bias: Evidence from Survey Data. Review of Economics and Statistics, 85, 307-312.

U.S. Census Bureau, 2009. 2009 Annual Survey of State Government Finances, http://www.census.gov/govs/state/. 
Table 1: Number of Investments by Source and Type

The top panel shows the number of investments by source and investment type. The bottom panel shows investments by type.

\begin{tabular}{|c|c|c|c|}
\hline Source & & Investments & Share \\
\hline Preqin Only & & 10,789 & $57 \%$ \\
\hline VE/V1 Only & & 380 & $2 \%$ \\
\hline Capital IQ Only & & 1,024 & $5 \%$ \\
\hline Preqin and VE/V1 & & 2,159 & $11 \%$ \\
\hline Preqin and Capital IQ & & 2,393 & $13 \%$ \\
\hline VE/V1 and Capital IQ & & 806 & $4 \%$ \\
\hline Preqin, VE/V1, and Capital IQ & & 1,277 & $7 \%$ \\
\hline Total & & 18,828 & $100 \%$ \\
\hline Type & & Investments & Share \\
\hline Buyout & & 5,682 & $30 \%$ \\
\hline Venture Capital & & 5,562 & $30 \%$ \\
\hline General & 3,329 & & \\
\hline Early Stage & 1,805 & & \\
\hline Late Stage & 373 & & \\
\hline Venture Debt & 55 & & \\
\hline Real Estate & & 2,489 & $13 \%$ \\
\hline Other & & 5,095 & $27 \%$ \\
\hline Fund of Funds & 1,508 & & \\
\hline Distressed Debt & 1,000 & & \\
\hline Mezzanine & 630 & & \\
\hline Natural Resources & 579 & & \\
\hline Balanced & 422 & & \\
\hline Secondaries & 320 & & \\
\hline Expansion & 195 & & \\
\hline Infrastructure & 153 & & \\
\hline Other & 288 & & \\
\hline Total & & 18,828 & $100 \%$ \\
\hline
\end{tabular}


Table 2: Number of Investments by Investment Type and Limited Partner (LP) Type

The table presents the number of investments by type of LP and by type of investment. Percentages represent the percent of the total investments by the LP type in each row.

\begin{tabular}{|c|c|c|c|c|c|c|c|c|c|c|}
\hline Limited Partner (LP) Type & Buyout & & Venture & & Real Estate & & Other & & & \\
\hline \multirow[t]{2}{*}{ Public Sector Pension Fund } & 3,773 & & 3,020 & & 1,894 & & 3,112 & & 11,799 & \\
\hline & $32 \%$ & & $26 \%$ & & $16 \%$ & & $26 \%$ & & $100 \%$ & \\
\hline \multirow[t]{2}{*}{ Private Sector Pension Fund } & 425 & & 391 & & 87 & & 202 & & 1,105 & \\
\hline & $38 \%$ & & $35 \%$ & & $8 \%$ & & $18 \%$ & & $100 \%$ & \\
\hline \multirow[t]{2}{*}{ Endowment } & 769 & & 1,180 & & 237 & & 776 & & 2,962 & \\
\hline & $26 \%$ & & $40 \%$ & & $8 \%$ & & $26 \%$ & & $100 \%$ & \\
\hline \multirow[t]{2}{*}{ Private Institution } & & 462 & & 781 & & 59 & & 222 & & 1,524 \\
\hline & & $30 \%$ & & $51 \%$ & & $4 \%$ & & $15 \%$ & & $100 \%$ \\
\hline \multirow[t]{2}{*}{ Public Institution } & & 307 & & 399 & & 178 & & 554 & & 1,438 \\
\hline & & $21 \%$ & & $28 \%$ & & $12 \%$ & & $39 \%$ & & $100 \%$ \\
\hline \multirow[t]{2}{*}{ Foundation } & 715 & & 971 & & 271 & & 1,005 & & 2,962 & \\
\hline & $24 \%$ & & $33 \%$ & & $9 \%$ & & $34 \%$ & & $100 \%$ & \\
\hline \multirow[t]{2}{*}{ Total } & 5,682 & & 5,562 & & 2,489 & & 5,095 & & 18,828 & \\
\hline & $30 \%$ & & $30 \%$ & & $13 \%$ & & $27 \%$ & & & \\
\hline
\end{tabular}




\section{Table 3: Summary Statistics}

The first two panels show summary statistics for the key performance measures, net IRR and multiple of invested capital, by LP type. The third panel shows the distribution of vintages by decade and LP type. The fourth panel shows the size of LP's private equity (PE) portfolios in 2009. The fifth panel tabulates state-level variables.

Endowment

Foundation

Private Sector Pension Fund

Public Sector Pension Fund

All

Endowment

Foundation

Private Sector Pension Fund

Public Sector Pension Fund

All

Endowment

Foundation

Private Sector Pension Fund

Public Sector Pension Fund

Total

Endowment

Foundation

Private Sector Pension Fund

Public Sector Pension Fund

Total

Corruption Index (Glaeser-Saks)

Corruption Survey (Boylan-Long)

Corruption Boylan-Long Non-Response

Population

Ln(Population)

Growth in Nominal GSP (varies by year)

WY excluded because no LPs in sample. DC included in all but Glaeser-Saks (no data). DC included in Boylan-

Long non-response.

Commitment Size $(\$ M)$

Panel B: Multiple (x)

\begin{tabular}{rrrr}
\hline \multicolumn{1}{c}{ Mean } & \multicolumn{1}{c}{ Median } & \multicolumn{1}{c}{ Std Dev } & \multicolumn{1}{c}{. } \\
\hline 1.79 & 1.18 & 2.90 & 2,532 \\
1.66 & 1.19 & 2.80 & 2,371 \\
1.57 & 1.25 & 1.93 & 978 \\
1.36 & 1.09 & 1.44 & 11,091
\end{tabular}

Panel C: Vintage

\begin{tabular}{rrrrr}
\hline $1969-1979$ & $1980-1989$ & \multicolumn{1}{c}{$1990-1999$} & $2000-2010$ \\
\hline 2 & 95 & 1,017 & 1,844 \\
& 0 & 63 & 826 & 2,064 \\
& 0 & 75 & 420 & 608 \\
& 7 & 493 & 3,256 & 8,041 \\
9 & 726 & 5,519 & 12,557
\end{tabular}

Panel D: Size of LP's PE Portfolio in 2009, \$M, LP Level

\begin{tabular}{cccc}
\hline Mean & Median & Std Dev & N \\
\hline 281 & 81 & 649 & 168 \\
153 & 33 & 564 & 193 \\
1186 & 317 & 2595 & 84 \\
1176 & 158 & 3054 & 186 \\
626 & 89 & 2017 & 631
\end{tabular}

Panel E: State Variables

\begin{tabular}{rrrr}
\hline \multicolumn{1}{c}{ Mean } & \multicolumn{1}{c}{ Median } & \multicolumn{1}{c}{ Std Dev } & $\mathrm{N}$ \\
\hline 0.28 & 0.25 & 0.14 & 49 \\
3.22 & 3.49 & 1.46 & 50 \\
0.08 & 0.00 & 0.27 & 50 \\
$6,129,246$ & $4,403,095$ & $6,803,777$ & 50 \\
15.14 & 15.30 & 1.02 & 50 \\
0.060 & 0.057 & 0.041 & 1500
\end{tabular}

Panel F: Investment Variables

\begin{tabular}{crrrr}
\hline Mean & \multicolumn{2}{c}{ Median } & Std Dev & N \\
\hline & 46 & 20 & 84 & 10,833
\end{tabular}

Panel A: Net IRR

\begin{tabular}{rrrr}
\hline \multicolumn{1}{c}{ Mean } & \multicolumn{1}{c}{ Median } & \multicolumn{1}{c}{ Std Dev } & \multicolumn{1}{c}{} \\
\hline 12.01 & 6.10 & 35.73 & 2,268 \\
9.78 & 6.30 & 29.30 & 2,126 \\
8.41 & 6.45 & 24.50 & 910 \\
5.78 & 5.00 & 29.33 & 9,577 \\
7.46 & 5.40 & 30.22 & 14,881
\end{tabular}




\section{Table 4: Overweighting by LPs of In-State Investments, Pooled Across Time}

The table presents the share of in-state investments by LPs located in each state and the equal-weighted and valuedweighted home bias of the portfolios of LPs located in each state. Column (1) is the percentage of in-state investments made by LPs that are located in the state. Column (2) presents the overweighting relative to all investments, calculated as the percent of in-state investments in column (1) of this table minus the state's share of all investments by all LPs in the full sample (pooled over time). Column (3) presents the overweighting relative to all out-of-state investments, calculated as the percent of in-state investments in column (1) of this table minus the state's share of all investments by out-of-state LPs in the full sample (also pooled over time). Columns (4), (5) and (6) repeat the exercises in columns (2), (3) and (4), value-weighting the investments by the dollar value of capital committed to the fund by the LP, and including only investments for which the capital committed by the LP is known. WY has no LPs in our sample. Nine states without PE investments are not shown: AK, HI, KS, MS, MT, $\mathrm{ND}, \mathrm{NV}, \mathrm{SD}$, and WV. For three states (AL, AR, and NM), we have no investments with known commitment amount data.

\begin{tabular}{|c|c|c|c|c|c|c|}
\hline \multirow{3}{*}{ State(LP) } & \multicolumn{3}{|c|}{ Equal Weighted } & \multicolumn{3}{|c|}{ Value Weighted } \\
\hline & \multirow{2}{*}{$\begin{array}{c}\begin{array}{c}\text { Investments } \\
\text { by LPs }\end{array} \\
\% \text { in state } \\
(1) \\
\end{array}$} & \multicolumn{2}{|c|}{$\begin{array}{l}\text { Home Bias, } \% \text { of } \\
\text { Portfolio, Relative to }\end{array}$} & \multirow{2}{*}{$\begin{array}{c}\text { Investments } \\
\text { by LPs } \\
\% \text { in state } \\
(4) \\
\end{array}$} & \multicolumn{2}{|c|}{$\begin{array}{l}\text { Home Bias, } \% \text { of } \\
\text { Portfolio, Relative to }\end{array}$} \\
\hline & & $\frac{\text { All LPs }}{(2)}$ & $\begin{array}{l}\text {-of-State } \\
\text { LPs } \\
(3)\end{array}$ & & $\frac{\text { All LPs }}{(5)}$ & $\frac{\text { Out-of-State LP }}{(6)}$ \\
\hline$\overline{\mathrm{AL}}$ & $0.0 \%$ & $0.0 \%$ & $0.0 \%$ & & & \\
\hline AR & $2.9 \%$ & $2.9 \%$ & $2.9 \%$ & & & \\
\hline AZ & $1.0 \%$ & $1.0 \%$ & $1.0 \%$ & $0.6 \%$ & $0.6 \%$ & $0.6 \%$ \\
\hline CA & $35.1 \%$ & $9.3 \%$ & $11.7 \%$ & $25.0 \%$ & $5.3 \%$ & $10.2 \%$ \\
\hline $\mathrm{CO}$ & $7.9 \%$ & $6.9 \%$ & $6.9 \%$ & $4.5 \%$ & $3.9 \%$ & $3.9 \%$ \\
\hline CT & $10.4 \%$ & $3.5 \%$ & $2.3 \%$ & $28.7 \%$ & $22.9 \%$ & $22.6 \%$ \\
\hline $\mathrm{DC}$ & $3.6 \%$ & $2.1 \%$ & $1.8 \%$ & $22.1 \%$ & $18.9 \%$ & $18.5 \%$ \\
\hline $\mathrm{DE}$ & $0.0 \%$ & $0.0 \%$ & $0.0 \%$ & $0.0 \%$ & $0.0 \%$ & $0.0 \%$ \\
\hline FL & $0.7 \%$ & $0.0 \%$ & $-0.1 \%$ & $0.1 \%$ & $-0.2 \%$ & $-0.2 \%$ \\
\hline GA & $2.5 \%$ & $2.3 \%$ & $2.3 \%$ & $0.0 \%$ & $-0.1 \%$ & $-0.1 \%$ \\
\hline IA & $0.9 \%$ & $0.9 \%$ & $0.9 \%$ & $0.2 \%$ & $0.1 \%$ & $0.1 \%$ \\
\hline ID & $3.1 \%$ & $3.1 \%$ & $3.1 \%$ & $1.3 \%$ & $1.3 \%$ & $1.3 \%$ \\
\hline IL & $18.7 \%$ & $11.5 \%$ & $11.8 \%$ & $21.8 \%$ & $17.3 \%$ & $17.4 \%$ \\
\hline IN & $5.2 \%$ & $5.0 \%$ & $5.1 \%$ & $0.8 \%$ & $0.7 \%$ & $0.8 \%$ \\
\hline KY & $3.3 \%$ & $3.3 \%$ & $3.3 \%$ & $0.9 \%$ & $0.9 \%$ & $0.9 \%$ \\
\hline LA & $0.8 \%$ & $0.8 \%$ & $0.8 \%$ & $0.1 \%$ & $0.1 \%$ & $0.1 \%$ \\
\hline MA & $41.5 \%$ & $24.6 \%$ & $23.8 \%$ & $26.3 \%$ & $16.1 \%$ & $15.1 \%$ \\
\hline MD & $3.3 \%$ & $2.4 \%$ & $2.3 \%$ & $2.7 \%$ & $2.2 \%$ & $2.1 \%$ \\
\hline ME & $0.0 \%$ & $0.0 \%$ & $0.0 \%$ & $0.0 \%$ & $0.0 \%$ & $0.0 \%$ \\
\hline MI & $1.4 \%$ & $1.1 \%$ & $1.1 \%$ & $0.9 \%$ & $0.7 \%$ & $0.7 \%$ \\
\hline $\mathrm{MN}$ & $9.7 \%$ & $8.9 \%$ & $9.0 \%$ & $8.6 \%$ & $7.1 \%$ & $7.2 \%$ \\
\hline MO & $2.3 \%$ & $2.2 \%$ & $2.2 \%$ & $0.3 \%$ & $0.3 \%$ & $0.3 \%$ \\
\hline $\mathrm{NC}$ & $6.9 \%$ & $6.4 \%$ & $6.5 \%$ & $7.2 \%$ & $6.8 \%$ & $6.9 \%$ \\
\hline $\mathrm{NE}$ & $8.0 \%$ & $8.0 \%$ & $8.0 \%$ & $3.1 \%$ & $3.0 \%$ & $3.0 \%$ \\
\hline $\mathrm{NH}$ & $2.0 \%$ & $2.0 \%$ & $2.0 \%$ & $2.0 \%$ & $2.0 \%$ & $2.0 \%$ \\
\hline NJ & $2.8 \%$ & $1.4 \%$ & $1.2 \%$ & $2.8 \%$ & $1.6 \%$ & $1.5 \%$ \\
\hline NM & $1.3 \%$ & $1.3 \%$ & $1.3 \%$ & & & \\
\hline NY & $28.0 \%$ & $4.6 \%$ & $3.4 \%$ & $40.0 \%$ & $1.9 \%$ & $-2.0 \%$ \\
\hline $\mathrm{OH}$ & $19.8 \%$ & $18.2 \%$ & $18.7 \%$ & $7.3 \%$ & $6.7 \%$ & $6.9 \%$ \\
\hline OK & $0.0 \%$ & $-0.1 \%$ & $-0.2 \%$ & $0.0 \%$ & $0.0 \%$ & $0.0 \%$ \\
\hline OR & $2.2 \%$ & $2.0 \%$ & $2.1 \%$ & $0.5 \%$ & $0.3 \%$ & $0.3 \%$ \\
\hline PA & $13.2 \%$ & $11.5 \%$ & $12.1 \%$ & $8.7 \%$ & $7.1 \%$ & $7.7 \%$ \\
\hline
\end{tabular}




$\begin{array}{lrrrrrr}\text { RI } & 8.6 \% & 7.8 \% & 7.7 \% & 9.7 \% & 8.2 \% & 8.1 \% \\ \text { SC } & 3.6 \% & 3.6 \% & 3.6 \% & 1.4 \% & 1.4 \% & 1.4 \% \\ \text { TN } & 12.8 \% & 12.5 \% & 12.5 \% & 0.0 \% & 0.0 \% & 0.0 \% \\ \text { TX } & 17.2 \% & 11.4 \% & 11.2 \% & 14.2 \% & 5.6 \% & 5.5 \% \\ \text { UT } & 2.9 \% & 2.9 \% & 2.9 \% & 6.5 \% & 6.5 \% & 6.5 \% \\ \text { VA } & 2.0 \% & 1.3 \% & 1.3 \% & 3.7 \% & 3.1 \% & 3.1 \% \\ \text { VT } & 0.0 \% & 0.0 \% & -0.1 \% & 0.0 \% & 0.0 \% & 0.0 \% \\ \text { WA } & 4.6 \% & 3.8 \% & 3.7 \% & 1.2 \% & 0.9 \% & 1.0 \% \\ \text { WI } & 3.8 \% & 3.7 \% & 3.8 \% & 2.1 \% & 2.0 \% & 2.1 \% \\ \text { Mean } & 5.76 \% & 3.80 \% & 3.80 \% & 6.72 \% & 4.09 \% & 4.09 \% \\ \text { Median } & 2.53 \% & 2.13 \% & 2.06 \% & 2.08 \% & 1.74 \% & 1.42 \%\end{array}$


Table 5: Overweighting by LPs of In-State Investments, Rolling 5-Year Benchmarks

The table presents the equal-weighted and valued-weighted home bias of the portfolios of LPs located in each state using rolling 5-year benchmarks. Column (1) is the number of [LP x vintage] observations in which PE investments were made, which constitutes the number of observations used in the equal-weighted calculation. Column (2) presents the overweighting relative to all investments, calculated as the average percent of in-state investments minus the state's share of all investments by all LPs in the full sample over the preceding five years. Column (3) presents the overweighting relative to all out-of-state investments, calculated as the mean over the sample period of the percent of in-state investments in each year minus the state's share of all investments by out-of-state LPs in the full sample over the preceding five years. Column (4) is the number of [LP x vintage] observations used in the value-weighted calculation, which is the subset of column (1) for which commitment data are available. Columns (5) and (6) repeat the exercises in columns (2) and (3), value-weighting the investments by the dollar value of capital committed to the fund by the LP, and including only investments for which the capital committed by the LP is known. WY has no LPs in our sample. Nine states without PE investments are not shown: AK, HI, KS, MS, MT, $\mathrm{ND}, \mathrm{NV}, \mathrm{SD}$, and WV. For three states (AL, AR, and NM), we have no investments with known commitment amount data.

Equal Weighted

\begin{tabular}{|c|c|c|}
\hline $\begin{array}{c}\text { Observation } \\
\text { Count }\end{array}$ & $\begin{array}{l}\text { Home Bi } \\
\text { Portfolio, }\end{array}$ & $\begin{array}{l}\% \text { of } \\
\text { tive to }\end{array}$ \\
\hline LP x Vintage & All LPs & $\begin{array}{l}\text {-of-State } \\
\text { LPs }\end{array}$ \\
\hline (1) & $(2)$ & (3) \\
\hline 2 & $0.0 \%$ & 0.0 \\
\hline 12 & $4.8 \%$ & $4.8^{\circ}$ \\
\hline 30 & $1.8 \%$ & $1.8^{\circ}$ \\
\hline 548 & $13.2 \%$ & $15.2^{\circ}$ \\
\hline 124 & $10.3 \%$ & 10.4 \\
\hline 97 & $3.5 \%$ & 2.2 \\
\hline 63 & $0.5 \%$ & $0.2 \%$ \\
\hline 18 & $0.0 \%$ & $0.0^{\circ}$ \\
\hline 53 & $0.6 \%$ & $0.5^{\circ}$ \\
\hline 52 & $2.2 \%$ & 2.2 \\
\hline 53 & $1.5 \%$ & $1.6^{\circ}$ \\
\hline 26 & $2.3 \%$ & $2.3^{\circ}$ \\
\hline 322 & $22.3 \%$ & $22.7 \%$ \\
\hline 83 & $9.8 \%$ & $9.9^{\circ}$ \\
\hline 37 & $7.6 \%$ & 7.6 \\
\hline 47 & $3.6 \%$ & $3.6^{\circ}$ \\
\hline 394 & $31.7 \%$ & $31.0 \%$ \\
\hline 106 & $3.4 \%$ & $3.3^{\circ}$ \\
\hline 19 & $0.0 \%$ & $0.0 \%$ \\
\hline 213 & $1.0 \%$ & $1.0^{\circ}$ \\
\hline 126 & $13.3 \%$ & $13.5^{\circ}$ \\
\hline 96 & $4.3 \%$ & $4.3^{\circ}$ \\
\hline 95 & $10.6 \%$ & $10.7^{\circ}$ \\
\hline 20 & $4.3 \%$ & $4.4^{\circ}$ \\
\hline 35 & $1.6 \%$ & $1.6^{\circ}$ \\
\hline 52 & $2.7 \%$ & 2.5 \\
\hline 19 & $7.9 \%$ & 7.9 \\
\hline 553 & $5.2 \%$ & $3.8^{\circ}$ \\
\hline 180 & $32.4 \%$ & $33.1 \%$ \\
\hline 24 & $-0.1 \%$ & -0.2 \\
\hline
\end{tabular}

Value Weighted

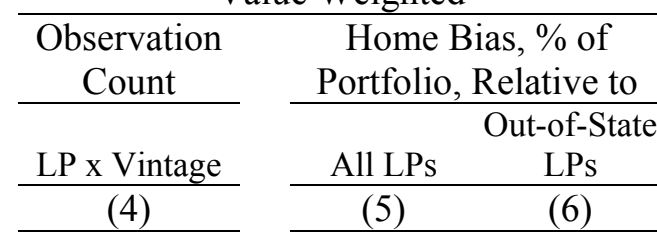

21

339

$5.7 \% \quad 5.7 \%$

$13.5 \% \quad 18.5 \%$

$8.9 \% \quad 9.1 \%$

$14.1 \% \quad 13.9 \%$

$1.6 \% \quad 1.2 \%$

$0.0 \% \quad 0.0 \%$

$-0.1 \% \quad-0.1 \%$

$-0.1 \% \quad-0.1 \%$

$0.4 \% \quad 0.4 \%$

$0.6 \% \quad 0.6 \%$

$24.3 \% \quad 24.5 \%$

$4.2 \% \quad 4.2 \%$

$8.0 \% \quad 8.0 \%$

$2.9 \% \quad 2.9 \%$

$36.1 \% \quad 35.0 \%$

$4.6 \% \quad 4.5 \%$

$0.0 \% \quad 0.0 \%$

$0.1 \% \quad 0.1 \%$

$8.3 \% \quad 8.3 \%$

$1.2 \% \quad 1.2 \%$

$4.3 \% \quad 4.3 \%$

$18.1 \% \quad 18.1 \%$

$2.2 \% \quad 2.2 \%$

$-0.3 \% \quad-0.4 \%$

$-1.2 \% \quad-5.6 \%$

$32.4 \% \quad 32.9 \%$

$0.0 \% \quad-0.1 \%$ 


$\begin{array}{lrrrrrr}\text { OR } & 66 & 3.1 \% & 3.1 \% & 41 & 5.6 \% & 5.6 \% \\ \text { PA } & 219 & 16.0 \% & 16.7 \% & 76 & 27.5 \% & 28.3 \% \\ \text { RI } & 35 & 12.3 \% & 12.2 \% & 20 & 11.4 \% & 11.3 \% \\ \text { SC } & 12 & 0.9 \% & 0.9 \% & 5 & 0.6 \% & 0.6 \% \\ \text { TN } & 30 & 18.9 \% & 18.9 \% & 5 & 0.0 \% & 0.0 \% \\ \text { TX } & 236 & 13.1 \% & 13.0 \% & 163 & 14.1 \% & 14.3 \% \\ \text { UT } & 25 & 6.7 \% & 6.7 \% & 7 & 16.8 \% & 16.8 \% \\ \text { VA } & 72 & 0.2 \% & 0.1 \% & 34 & 1.3 \% & 1.3 \% \\ \text { VT } & 21 & -0.1 \% & -0.1 \% & 15 & 0.0 \% & -0.1 \% \\ \text { WA } & 113 & 4.0 \% & 4.1 \% & 60 & 4.9 \% & 5.1 \% \\ \text { WI } & 98 & 4.0 \% & 4.1 \% & 54 & 0.7 \% & 0.7 \% \\ \text { Total } & 4,426 & & & 1,997 & & 7.17 \% \\ \text { Mean } & & 6.85 \% & 6.86 \% & & 3.51 \% & 3.52 \% \\ \text { Median } & & 4.00 \% & 3.79 \% & & & 3.20 \%\end{array}$




\section{Table 6: In-State Overweighting Overall, by LP Type, and by Investment Type}

The table presents overweighting of in-state investments, overall and by LP type, where the LP's in-state overweighting each year is calculated versus benchmarks based on the prior five years of investments. The first row shows statistics for the in-state investment indicator over all observations. The second row shows statistics for the 18,102 observations for which funds exist in the state of the LP (that is, without the 9 states that are excluded from Tables 4 and 5), including the expected in-state investment share based on the overall state share in the distribution.

\section{Sample \\ All \\ By LP Type}

Excluding Nine States

without PE Funds

Public Sector Pension

Private Sector Pension

Endowment

Public Institution

Private Institution

Foundation

By Investment Type

Buyout

Public Pension

Private Pension

Endowment

Foundation

Venture

Public Pension

Private Pension

Endowment

Foundation

Real Estate

Public Pension

Private Pension

Endowment
In-State Investments

$\frac{\text { mean std err }}{0.1673 \quad 0.003}$

18,102

0.1740

0.003

0.194

0.176

0.129

0.080

0.174

0.140

0.004
0.011
0.006
0.007
0.010
0.006

0.150

0.139

0.230

0.138

0.165

0.239

0.320

0.113

0.164

0.146

0.005

0.006

0.021

0.013

0.014

0.006

0.009

0.016

1,177

962

1,787
1,399
63
97

\subsection{2}

0.274

0.286

0.113

0.011

0.011

0.010

0.012

0.057

0.032
Excess over Baseline 1:

Share of Investments in

\begin{tabular}{c}
\multicolumn{2}{c}{ State by All LPs } \\
\hline mean std err
\end{tabular}

0.0776

$0.003^{* * *}$

Excess over Baseline 2:

Share of Investments in

State by Out-of-State LPs

mean std err

0.0807
Difference with Public

Pension mean std err

0.0776

$\begin{array}{ll}0.092 & 0.004^{* * *} \\ 0.065 & 0.011^{* * *} \\ 0.067 & 0.006^{* * *} \\ 0.062 & 0.007^{* * *} \\ 0.072 & 0.009^{* * *} \\ 0.037 & 0.006^{* * *}\end{array}$

0.051

0.053

0.053

0.062

0.028

0.115

0.150

0.051

0.088

0.068

0.127

0.149

0.110

0.048

41
$0.005^{* * *}$

$0.006^{* * *}$

$0.018^{* * *}$

$0.012 * * *$

$0.013 * *$

$0.005^{* * *}$

$0.008^{* * *}$

$0.013^{* * *}$

$0.010^{* * *}$

$0.009^{* * *}$

$0.010 * * *$

$0.011^{* * *}$

$0.052 * *$

0.030
$0.003 * * *$

0.097

0.062

0.067

0.063

0.070

0.038

$0.004 * * *$

$0.006 * * *$

$0.007 * * *$

$0.009 * * *$

$0.006^{* * *}$

$-0.036^{* *}$

$-0.030 * * *$

$-0.034 * * *$

$-0.027 * *$

$-0.060 * * *$

0.054

0.058

0.052

0.062

0.031

0.116

0.154

0.049

0.088

0.069

0.132

0.156

0.105

0.048

$0.005^{* * *}$

$0.006 * * *$

$0.018 * * *$

$0.012 * * *$

$-0.006$

0.004

$0.013 * *$

$-0.027$

$0.005 * * *$

$0.008^{* * *}$

$0.013 * * *$

$0.010 * * *$

$-0.105 * * *$

$0.009 * * *$

$0.066^{* * *}$

$0.010 * * *$

$0.012 * * *$

$0.052 * *$

0.031

$-0.051$

$-0.108 * *$ 


\begin{tabular}{|c|c|c|c|c|c|c|c|c|}
\hline Foundation & 228 & 0.162 & 0.024 & 0.028 & 0.024 & 0.028 & 0.024 & $-0.128 * * *$ \\
\hline Other & 4,500 & 0.143 & 0.005 & 0.061 & $0.005 * * *$ & 0.065 & $0.005 * * *$ & \\
\hline Public Pension & 2,718 & 0.157 & 0.007 & 0.072 & $0.007 * * *$ & 0.078 & $0.007 * * *$ & \\
\hline Private Pension & 194 & 0.180 & 0.028 & 0.069 & $0.024 * * *$ & 0.067 & $0.024 * * *$ & -0.011 \\
\hline Endowment & 686 & 0.102 & 0.012 & 0.058 & $0.011 * * *$ & 0.059 & $0.011^{* * *}$ & -0.019 \\
\hline Foundation & 902 & 0.124 & 0.011 & 0.028 & $0.010 * * *$ & 0.030 & $0.010 * * *$ & $-0.048 * * *$ \\
\hline \multicolumn{9}{|l|}{ By Time Period } \\
\hline $1980 \mathrm{~s}$ & 694 & 0.216 & 0.016 & 0.125 & $0.015 * * *$ & 0.125 & $0.015 * * *$ & \\
\hline 1990s & 5006 & 0.187 & 0.006 & 0.097 & $0.005 * * *$ & 0.098 & $0.005 * * *$ & \\
\hline $2000 \mathrm{~s}$ & 11,694 & 0.173 & 0.004 & 0.113 & $0.003 * * *$ & 0.117 & $0.003 * * *$ & \\
\hline
\end{tabular}




\section{Table 7: Overweighting of In-State Investments and General LP Characteristics}

The table presents regressions in which the dependent variable is the LP's excess share of in-state investments over the previous 5 years, relative to the benchmark representing the share of investments in the state by out-of-state LP's over the preceding five year period. The observation is an LP-year. The independent variables are the natural logarithm of the size the LP's private equity portfolio in dollar terms, the natural logarithm of the state population, the growth in nominal gross state product (GSP), and indicator variables for LP type (the omitted category is foundations). Standard errors are clustered at the LP-state level. All models include vintage year fixed effects. *** significant at the $1 \%$ level, ** significant at the 5\% level, * significant at the $10 \%$ level.

Dependent Variable: Excess Share of In-State Investments by LP

$\ln ($ Size of PE Portfolio)

$\ln ($ Population of State)

Growth in Nominal GSP

Endowment

Public Pension

Private Pension

Observations

R-Squared
$-0.027 * * *$

(0.00)

-0.027
$(0.00)$

(0.24)

$0.122 * * *$

(0.03)

0.033

(0.31)

4407

0.07
$-0.029 * * *$

(0.00)

$0.031 * * *$

(0.01)

0.019

(0.02)

$0.131 * * *$

(0.03)

0.039

(0.03)

4407

0.09
$-0.030 * * *$

(0.00)

$0.030 * * *$

(0.01)

$-0.109$

$(0.23)$

0.015

(0.02)

$0.131 * * *$

0.035

(0.18) 


\section{Table 8: Net IRR Differences}

This table shows t-tests of differences in net IRR between in-state and out-of-state investments. The left panel analyzes the raw IRR, the middle panel examines the IRR minus the mean of all other observations in the same state and vintage of the investment fund (the GP), and the right panel examines the IRR minus the mean of all other observations in the same state, vintage and investment type of the investment fund (buyout, venture, real estate, other). Each set of three rows consists of a row of means, a row of standard deviations, and a third row with observation counts and t-statistics. The t-statistic is for the test with null hypothesis that the difference between the outof-state IRRs and the in-state IRRs equals zero. The first three rows consider all observations, the next set of three rows considers only public pensions, the next set of rows considers only private pensions, and so forth. $* * *$ significant at the $1 \%$ level.

All

IRR

Public Pension

Private Pension

Endowment

Public Endowment

Private Endowment

Foundation

\begin{tabular}{|c|c|c|c|c|c|}
\hline \multicolumn{3}{|c|}{ IRR } & \multicolumn{3}{|c|}{ IRR Minus [State $\mathrm{x}$ Vintage] Mean } \\
\hline Out of State & In State & Difference & Out of State & In State & Difference \\
\hline 7.92 & 5.19 & 2.73 & 0.48 & -2.39 & 2.87 \\
\hline 0.28 & 0.54 & 0.66 & 0.22 & 0.47 & 0.53 \\
\hline 12,400 & 2,481 & $4.11 * * *$ & 12400 & 2481 & $5.38 * * *$ \\
\hline 6.29 & 3.51 & 2.78 & -0.05 & -3.80 & 3.75 \\
\hline 0.34 & 0.66 & 0.77 & 0.27 & 0.60 & 0.63 \\
\hline 7825 & 1752 & $3.59 * * *$ & 7825 & 1752 & $5.97 * * *$ \\
\hline 8.58 & 7.63 & 0.94 & -1.77 & -3.54 & 1.77 \\
\hline 0.90 & 1.85 & 2.15 & 0.75 & 1.41 & 1.77 \\
\hline 753 & 157 & 0.44 & 753 & 157 & 1.00 \\
\hline 12.16 & 10.95 & 1.22 & 2.39 & 1.76 & 0.63 \\
\hline 0.82 & 1.66 & 2.26 & 0.65 & 1.21 & 1.77 \\
\hline 1982 & 286 & 0.54 & 1982 & 286 & 0.35 \\
\hline 8.08 & 3.31 & 4.77 & 1.06 & 1.66 & -0.60 \\
\hline 1.04 & 2.01 & 3.68 & 0.83 & 1.69 & 2.92 \\
\hline 1021 & 84 & 1.30 & 1021 & 84 & -0.20 \\
\hline 16.50 & 14.13 & 2.38 & 3.80 & 1.80 & 2.00 \\
\hline 1.28 & 2.16 & 2.96 & 1.01 & 1.57 & 2.33 \\
\hline 961 & 202 & 0.80 & 961 & 202 & 0.86 \\
\hline 10.00 & 8.40 & 1.60 & 1.59 & 2.70 & -1.11 \\
\hline 0.70 & 1.38 & 1.86 & 0.57 & 1.04 & 1.49 \\
\hline 1840 & 286 & 0.86 & 1840 & 286 & -0.74 \\
\hline
\end{tabular}

IRR Minus [State $x$ Vintage $x$ Type]

\begin{tabular}{|c|c|c|}
\hline Out of State & In State & Difference \\
\hline 0.34 & -1.68 & 2.02 \\
\hline 0.18 & 0.37 & 0.44 \\
\hline 12400 & 2481 & $4.63 * * *$ \\
\hline-0.02 & -2.62 & 2.60 \\
\hline 0.22 & 0.46 & 0.20 \\
\hline 7825 & 1752 & $13.24 * * *$ \\
\hline-0.96 & -1.93 & 0.96 \\
\hline 0.63 & 1.21 & 1.48 \\
\hline 753 & 157 & 0.65 \\
\hline 1.57 & 0.65 & 0.92 \\
\hline 0.54 & 0.95 & 1.48 \\
\hline 1982 & 286 & 0.63 \\
\hline 0.77 & -0.86 & 1.62 \\
\hline 0.69 & 1.10 & 2.44 \\
\hline 1021 & 84 & 0.66 \\
\hline 2.43 & 1.27 & 1.16 \\
\hline 0.85 & 1.26 & 1.93 \\
\hline 961 & 202 & 0.60 \\
\hline 1.04 & 1.84 & -0.80 \\
\hline 0.47 & 0.92 & 1.24 \\
\hline 1840 & 286 & -0.65 \\
\hline
\end{tabular}


Table 9: Excess Share and Performance for Public Sector Pension Funds

This table examines the relation between whether an investment is in-state and performance. The level of observation is an investment. The variable In-State is an indicator for whether the investment is in-state. The variable In Neighbor State is an indicator for whether the investment is in a neighboring state. The variable Excess LP In-State Share is the difference between the LP's in-state share and the predicted in-state share based on the second benchmark (the state's share of all investments that are not in-state investments over the preceding five year period). The first three columns examine performance measures adjusted by the mean performance for all

investments in the sample that are made in the same state and vintage, the second three columns examine performance measures adjusted by the mean performance for all investments in the sample that are made in the same state and vintage and investment type (buyout, venture, real estate, other). In Panel A, the performance measure is net IRR. In Panel B, the performance measure is multiple of invested capital. Standard errors are clustered by LP state. *** significant at the $1 \%$ level, ** significant at the $5 \%$ level, * significant at the $10 \%$ level.

Panel A: Net IRR

\section{In-State}

In Neighbor State

Excess LP In-State Share

In-State x Excess LP Share

Constant

$-0.048$

$(0.370)$
State x Vintage] Mean

\begin{tabular}{ccc}
\multicolumn{3}{c}{ Net IRR $-[$ State $\mathrm{x}$ Vintage] } \\
\hline$-3.750^{* * *}$ & $-3.718^{* * *}$ & $-3.558^{* * *}$ \\
$(1.070)$ & $(1.037)$ & $(0.800)$ \\
& 0.330 & 0.556 \\
& $(0.975)$ & $(1.002)$ \\
& & $-6.830^{* *}$
\end{tabular}

$$
\text { (2.781) }
$$

4.611

(5.600)

\begin{abstract}
0.322
\end{abstract}
(0.490)

$(0.405)$

$9577 \quad 9577$

9051

$(0.220)$ Net IRR - [State x Vintage x Fund Type] Mean

Observations

9577

(0.234)

$(1.142)$

0.615

(0.707)

$(1.180)$

(0.707)

$-1.967 * * *$

$(0.514)$

0.711

$(0.750)$

$-4.223 *$

(2.189)

0.724

(4.912)

0.164

(0.291)

Panel B: Multiple of Invested Capital

\section{In-State}

In Neighbor State

Excess LP In-State Share

In-State x Excess LP Share

Constant

Observations

\begin{tabular}{c} 
Mult \\
\hline$-0.085^{*}$ \\
$(0.050)$
\end{tabular}

Multip

(0.050)

-0.0
0.0
0.0

$-0.085^{*}$
0.048
0.002
0.052

-

$-\frac{\mathrm{M}}{20.0}$

$(0.078)$

0.006

$(0.055)$

$-0.017$

(0.179)

0.338

$(0.276)$

$-0.053 * * * \quad-0.053 * * *$

$(0.020)$

0.019

$-0.054 * * *$

$(0.020)$

11091

10483

11091
Multiple - [State x Vintage x Fund Type] Mean

$-0.074^{*}$

$(0.040)$

$-0.073^{*}$

$(0.041)$

0.017

$-0.105^{* *}$

(0.031)

$(0.053)$

0.017

(0.033)

0.014

(0.123)

0.121

(0.263)

$-0.039^{* *}$

(0.016) 


\section{Table 10: Size, Corruption, and Home-State Overweighting}

The dependent variable is the difference between the LP's in-state share over the preceding five year period and the predicted in-state share based on the second five-year rolling benchmark (the state's share of all investments that are not in-state investments over the preceding five year period). The level of observation is an LP-year. The corruption index is from Glaeser and Saks (2006). The Corruption BL Survey is based on Boylan and Long as reported in the New York Times by Marsh (2008). The BL Non-Response variable is a corruption indicator for whether no state house reporters responded to the corruption survey. Teachers is an indicator for whether the pension system represents at least some teachers, and public safety is an indicator for whether the pension system represents at least some public safety officials. All models include vintage year fixed effects. Standard errors are clustered by LP-state. $* * *$ significant at the $1 \%$ level, ** significant at the $5 \%$ level, * significant at the $10 \%$ level.

Dependent Variable: Excess Share of In-State Investments by LP

\begin{tabular}{|c|c|c|c|c|c|}
\hline \multirow{3}{*}{ Corruption Index } & \multicolumn{5}{|c|}{ Public Pension Funds Only } \\
\hline & $0.547 * * *$ & $0.573 * * *$ & $0.526 * * *$ & & $0.550 * * *$ \\
\hline & $(0.18)$ & $(0.17)$ & $(0.19)$ & & $(0.20)$ \\
\hline \multirow[t]{2}{*}{$\ln ($ Size of PE Portfolio) } & & $-0.033 * *$ & $-0.034 * *$ & $-0.019 *$ & -0.022 \\
\hline & & $(0.02)$ & $(0.02)$ & $(0.01)$ & $(0.01)$ \\
\hline \multirow[t]{2}{*}{$\ln$ (Population of State) } & & & 0.023 & $0.047 *$ & 0.037 \\
\hline & & & $(0.03)$ & $(0.03)$ & $(0.03)$ \\
\hline \multirow[t]{2}{*}{ Corruption BL Survey } & & & & $0.049 * *$ & 0.005 \\
\hline & & & & $(0.02)$ & $(0.03)$ \\
\hline \multirow{2}{*}{\multicolumn{2}{|c|}{ Corruption BL Non-Response }} & & & $0.356^{* * *}$ & $0.206 * *$ \\
\hline & & & & $(0.09)$ & $(0.09)$ \\
\hline \multirow[t]{2}{*}{ Teachers } & & & & & 0.022 \\
\hline & & & & & $(0.05)$ \\
\hline \multirow[t]{2}{*}{ Public Safety } & & & & & -0.002 \\
\hline & & & & & $(0.03)$ \\
\hline Observations & 1930 & 1923 & 1923 & 1923 & 1923 \\
\hline R-Squared & 0.09 & 0.14 & 0.15 & 0.17 & 0.20 \\
\hline
\end{tabular}

\begin{tabular}{lccccc}
\cline { 2 - 5 } Corruption Index & $-0.366^{*}$ & 0.073 & $-0.704^{* *}$ & -0.214 & -0.361 \\
& $(0.22)$ & $(0.19)$ & $(0.28)$ & $(0.17)$ & $(0.30)$ \\
$\ln$ (Size of PE Portfolio) & $-0.023^{* * *}$ & -0.014 & $-0.281 * * *$ & -0.013 & $-0.038^{* * *}$ \\
& $(0.01)$ & $(0.01)$ & $(0.02)$ & $(0.01)$ & $(0.01)$ \\
$\ln$ (Population of State) & $0.066^{* * *}$ & 0.033 & $0.083 * * *$ & 0.005 & $0.063^{*}$ \\
& $(0.01)$ & $(0.02)$ & $(0.03)$ & $(0.05)$ & $(0.03)$ \\
Observations & 989 & 398 & 591 & 425 & 1007 \\
R-Squared & 0.09 & 0.11 & 0.14 & 0.07 & 0.10 \\
\hline
\end{tabular}


Table 11: State Corruption and Performance for Different Types of LPs

The dependent variables are the performance measures: Net IRR demeaned by state-vintage cell in Panel A, and Multiple of Invested Capital demeaned by state-vintage cell in Panel B. The corruption index is from Glaeser and Saks (2006).

\begin{tabular}{lcccc}
\hline \multicolumn{4}{c}{ Panel A: Dependent Variable Net IRR Minus State x Vintage Mean } \\
\hline \multirow{2}{*}{ In-State } & \multicolumn{1}{c}{ Public Pension Funds Only } & \multicolumn{2}{c}{ All Other LPs } \\
& -5.95 & -9.61 & 3.78 & 5.28 \\
Corruption Index & $(2.45)^{* *}$ & $(6.47)$ & $(2.89)$ & $(4.81)$ \\
& 6.28 & 25.82 & 2.48 & 11.36 \\
Corruption x In-State Investment & $(3.26)^{*}$ & $(17.64)$ & $(3.59)$ & $(11.17)$ \\
& 7.35 & 7.63 & -13.23 & -13.90 \\
$\ln ($ size of LP's PE portfolio) & $(6.62)$ & $(5.97)$ & $(6.61)^{*}$ & $(6.29)^{* *}$ \\
& & 0.62 & & 0.77 \\
$\ln ($ size) x In-State & & $(0.64)$ & & $(0.51)$ \\
& & 0.49 & & -0.21 \\
$\ln ($ size) x Corruption Index & & $(0.69)$ & & $(0.81)$ \\
& & -2.67 & & -1.50 \\
Constant & -1.75 & $(2.49)$ & & $(2.30)$ \\
& $(0.86)^{* *}$ & -6.30 & 0.70 & -3.91 \\
$R^{2}$ & 0.01 & $(4.82)$ & $(1.26)$ & $(2.90)$ \\
$N$ & 9564 & 0.01 & 0.00 & 0.00 \\
\hline
\end{tabular}

\begin{tabular}{lcccc}
\hline \multicolumn{4}{c}{ Panel B: Dependent Variable $=$ Multiple Minus State $x$ Vintage Mean } & \\
\hline & \multicolumn{1}{c}{ Public Pension Funds Only } & \multicolumn{1}{c}{ All Other LPs } \\
In-State & -0.24 & -0.27 & 0.58 & 0.46 \\
& $(0.07)^{* * *}$ & $(0.10)^{* *}$ & $(0.29)^{*}$ & $(0.27)^{*}$ \\
Corruption Index & 0.24 & 1.38 & 0.02 & 0.17 \\
& $(0.15)$ & $(0.61)^{* *}$ & $(0.31)$ & $(0.85)$ \\
Corruption x In-State Investment & 0.53 & 0.54 & -1.52 & -1.50 \\
& $(0.20)^{* *}$ & $(0.24)^{* *}$ & $(0.70)^{* *}$ & $(0.70)^{* *}$ \\
$\ln ($ size of LP's PE portfolio) & & 0.03 & & 0.03 \\
& & $(0.02)$ & & $(0.04)$ \\
$\ln ($ size) x In-State & & 0.00 & & 0.02 \\
& & $(0.01)$ & & $(0.05)$ \\
$\ln ($ size) x Corruption Index & -0.16 & & -0.02 \\
& & $(0.08)^{*}$ & & $(0.18)$ \\
Constant & -0.12 & -0.34 & 0.11 & -0.09 \\
& $(0.04)^{* * *}$ & $(0.15)^{* *}$ & $(0.10)$ & $(0.22)$ \\
$R^{2}$ & 0.00 & 0.00 & 0.00 & 0.00 \\
$N$ & 11076 & 11070 & 5819 & 5819 \\
\hline
\end{tabular}

$* p<0.1 ; * * p<0.05 ; * * * p<0.01$. Standard errors are clustered by LP state. 
Table 12: Public Pension Home-State Weighting and Performance, Pooled Across Years This table shows unadjusted public pension fund home-state weighting and performance statistics, pooled across years. The first column shows the in-state share of public pension fund PE investments. The second column shows the percent of PE investments in the state by out-of-state public pension LPs. The net IRR columns show the net IRR of different investments. The first net IRR column shows the net IRR of in-state public pension PE investments by in-state LPs. The second net IRR column shows the net IRR of out-of-state public pension PE investments by instate LPs. The third column shows the net IRR of public pension PE investments in the state by out-of-state LPs. Only the 25 states for which all variables could be calculated are shown.

$$
\% \mathrm{PE}
$$

Public Investments in

Pension State by Out-
In-State of-State Public
Net IRR

\begin{tabular}{|c|c|c|}
\hline \multicolumn{3}{|c|}{ Net IRR } \\
\hline LP in & LP out & LP in \\
\hline GP in & GP in & GP out \\
\hline 6.03 & 10.85 & 5.10 \\
\hline 5.01 & -12.80 & 5.95 \\
\hline 4.40 & 9.96 & 12.95 \\
\hline-32.20 & -1.86 & 5.58 \\
\hline 12.90 & 2.37 & 1.13 \\
\hline 9.57 & 3.93 & 12.10 \\
\hline-0.57 & 0.49 & 11.84 \\
\hline-32.90 & 39.10 & 1.93 \\
\hline 2.24 & 11.33 & 10.86 \\
\hline-10.15 & -1.66 & -2.60 \\
\hline 6.11 & 8.77 & 7.55 \\
\hline-0.56 & 5.76 & 9.93 \\
\hline-18.63 & -8.62 & -3.48 \\
\hline 9.80 & 9.89 & 4.73 \\
\hline-6.70 & -0.80 & -6.88 \\
\hline 2.40 & 5.53 & -0.39 \\
\hline 3.35 & 1.52 & 0.26 \\
\hline 17.43 & 15.80 & 8.87 \\
\hline 0.49 & -13.01 & 5.80 \\
\hline 14.89 & 8.26 & 4.32 \\
\hline 14.50 & 3.46 & 18.97 \\
\hline-1.37 & 3.69 & 4.22 \\
\hline-0.38 & -1.56 & 16.50 \\
\hline 0.40 & -3.69 & 9.30 \\
\hline 4.83 & 3.00 & 5.01 \\
\hline 0.44 & 3.99 & 5.98 \\
\hline
\end{tabular}

Size of PE Program<smiles>CC(C)[SbH2]</smiles>

CA 33.5

21.6

$\mathrm{CO}$

7.3

0.8

13.7

5.7

1.8

0.8

0.6

3.1

0.0

6.8

0.0

44.2

13.7

0.9

0.3

0.6

0.4

0.1

1.6

25.5

0.6

0.0

0.9

PA

15.5

0.9

0.2

5.5

$\begin{array}{ll}\text { TX } & 16.9\end{array}$

0.7

0.4

\begin{tabular}{lrr} 
WA & 4.9 & \\
WI & 2.7 & 0.0 \\
\hline Avg & 12.3 & 3.6
\end{tabular}

Difference with LP(in)GP(in)

Avg

Wtd Avg

$\begin{array}{ll}-3.6 & -5.5 \\ -1.7 & -2.3\end{array}$

\section{9}

1.4

0.6

4.4

0.8

6.8

1.4

5.9

1.4

8.1

3.5

7.1

0.1

3.7

23.3

7.5

9.3

15.0

0.6

0.5

10.3

4.4

13.7

4.7 


\section{Table 13: Public Pension Home-State Overweighting and Underperformance Relative to Vintage Means}

This table shows public pension fund home-state weighting and performance statistics using calculations that reflect the vintage (year) composition of investments. The first column shows the predicted in-state share of public pension fund PE investments, using 5-year rolling benchmarks. The second column shows the excess in-state share relative to the predicted share in the first column. The net IRR columns show the net IRR of different investments. The first net IRR column shows the net IRR of in-state public pension PE investments by in-state LPs, relative to vintage means. The second net IRR column shows the net IRR of out-of-state public pension PE investments by in-state LPs. The third column shows the net IRR of public pension PE investments in the state by out-of-state LPs. Only the 25 states for which all variables could be calculated are shown.

\begin{tabular}{lrr} 
& \multicolumn{2}{c}{ In-State Share } \\
\cline { 2 - 3 } & \multicolumn{2}{c}{ 5yr Rolling } \\
\cline { 2 - 3 } CA & Predicted & Excess \\
\cline { 2 - 3 } CO & 1.0 & 9.1 \\
CT & 9.1 & 4.0 \\
DC & 1.3 & 1.4 \\
FL & 1.0 & 0.3 \\
ID & 0.0 & 3.0 \\
IL & 6.8 & 14.3 \\
IN & 0.0 & 3.9 \\
MA & 18.5 & 26.5 \\
MD & 1.2 & 5.3 \\
MI & 0.2 & 2.1 \\
MN & 0.6 & 10.8 \\
NC & 0.5 & 15.5 \\
NH & 0.1 & 2.0 \\
NJ & 1.4 & 0.9 \\
NY & 24.2 & 16.2 \\
OH & 1.1 & 25.3 \\
OR & 0.1 & 1.0 \\
PA & 1.0 & 16.6 \\
RI & 0.8 & 6.4 \\
TN & 0.2 & 27.7 \\
TX & 5.9 & 11.4 \\
VA & 0.7 & 1.8 \\
WA & 0.7 & 4.2 \\
WI & 0.0 & 2.7 \\
\hline Avg & 4.0 & 8.8
\end{tabular}

\begin{tabular}{rrr}
\multicolumn{4}{c}{ Net IRR - Vintage Mean } \\
\hline LP in & LP out & \multicolumn{1}{c}{ LP in } \\
GP in & GP in & \multicolumn{1}{c}{ GP out } \\
\hline-3.97 & -0.37 & 0.24 \\
5.40 & -5.13 & -3.21 \\
-12.50 & -0.46 & 0.29 \\
-15.29 & 0.45 & -2.75 \\
9.82 & 0.12 & -1.60 \\
0.00 & 0.00 & 1.45 \\
-1.87 & 0.81 & 1.88 \\
-2.55 & 0.00 & 2.82 \\
-10.69 & 0.44 & 0.91 \\
-17.91 & 0.35 & -1.30 \\
-1.62 & -0.14 & -2.58 \\
-1.74 & -0.78 & -0.59 \\
1.27 & -0.32 & -2.31 \\
0.00 & 0.00 & -11.36 \\
1.86 & -0.81 & -0.08 \\
-1.62 & 0.20 & -4.30 \\
-0.77 & 1.28 & -1.47 \\
0.00 & 0.00 & 0.35 \\
1.39 & -1.77 & 0.02 \\
-1.51 & -0.24 & -1.67 \\
0.00 & 0.00 & 8.63 \\
-5.98 & -1.40 & -0.99 \\
-0.25 & -0.06 & 3.12 \\
0.29 & 3.06 & -0.10 \\
0.00 & 0.00 & -2.08 \\
\hline-2.33 & -0.19 & -0.67
\end{tabular}

Size of PE

Program $\$$ bn

56.9

2.9

1.4

0.6

4.4

0.8

6.8

1.4

5.9

1.4

8.1

3.5

7.1

0.1

3.7

23.3

7.5

9.3

15.0

0.6

0.5

10.3

4.4

13.7

Difference with LP(in)GP(in)

$\begin{array}{ll}-2.1 & -1.7 \\ -1.9 & -1.3\end{array}$




\section{Table 14: Financial Effects of Overweighting and Underperformance for Public Pension Funds}

This table shows the financial effects of home-state overweighitng and underperformance for public pension funds. The left panel uses the investments by out-of-state LPs in the state as a benchmark, and the right panel uses the investments by state LPs outside of the state as a benchmark. Predicted and excess shares are based on the 5-year rolling benchmarks shown in Table 14. The first column is therefore the IRR difference between home-state investments and investments by out-of-state LPs in the state, times the predicted in-state share. The second column is the IRR difference between home-state investments and investments by out-of-state LPs in the state, times the excess in-state share. The third column is the sum of the first two columns. The right panel presents the analogous calculations for the benchmark of state LP investments outside of the state.

All figures in \$ millions per year

\section{Relative to Out-of-State LPs}

Investing in State LP(in)GP(in) - LP(out)GP(in)

\begin{tabular}{r} 
Predicted \\
\hline$(485)$ \\
3 \\
$(15)$ \\
$(1)$ \\
4 \\
0
\end{tabular}

ID

IL

IN

MA

MD

MI

$\mathrm{MN}$

$\mathrm{NC}$

$\mathrm{NH}$

NJ

NY

$\mathrm{OH}$

OR

PA

RI

TN

TX

VA

WA

WI

Total

Excess

(186)

24

(7)

(1)

1

0

(12)

(0)

(121)

(0)

1

\section{0}

(103)

(2)

\section{0}

\section{5}

(0)

0

(28)

(0)

(3)
(26)

(1)

(173)

(13)

(2)

(4)

17

0

1

(69)

(39)

0

78

(0)

0

(54)

(0)

(16)

Total

27

(22)

(3)

5

0

(38)

(1)

(294)

(16)

(3)

(4)

18

0

2

(171)

(41)

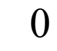

83

(1)

0

(82)

(0)

(18)
Relative to In-State LPs Investing Out-of-State

\begin{tabular}{rrr}
\hline \multicolumn{3}{c}{ LP(in)GP(in) - LP(in)GP(out) } \\
\hline Predicted & \multicolumn{1}{c}{ Excess } & \multicolumn{1}{c}{ Total } \\
\hline$(567)$ & $(217)$ & $(784)$ \\
2 & 19 & 22 \\
$(16)$ & $(7)$ & $(24)$ \\
$(1)$ & $(1)$ & $(2)$ \\
5 & 2 & 6 \\
$(0)$ & $(0)$ & $(0)$ \\
$(17)$ & $(36)$ & $(54)$ \\
$(0)$ & $(3)$ & $(3)$ \\
$(126)$ & $(180)$ & $(306)$ \\
$(3)$ & $(12)$ & $(15)$ \\
0 & 2 & 2 \\
$(0)$ & $(4)$ & $(5)$ \\
1 & 39 & 40 \\
0 & 0 & 0 \\
1 & 1 & 2 \\
151 & 101 & 252 \\
1 & 13 & 14 \\
$(0)$ & $(0)$ & $(0)$ \\
2 & 34 & 36 \\
0 & 0 & 0
\end{tabular}

(0)

(30)

(1)
(13)

(59)

(3)
(13)
22

(2)

36

)

\begin{tabular}{rrr}
$(1)$ & $(3)$ & $(4)$ \\
0 & 2 & 3 \\
0 & 3 & 3 \\
\hline$(598)$ & $(320)$ & $(919)$
\end{tabular}




\section{Table 15: Total Financial Effects as Share of Assets and Contributions}

This table present estimates of the financial effects of overweighting and underperformance as a share of total pension plans assets invested in private equity and as a share of annual contributions to the pension fund. The first column presents total pension plan PE assets by state. The second presents total annual contributions to pension plans by state. The second set of columns presents the annual financial effects due to the difference in the performance of in-state LPs on their in-state investments versus the performance of out-of-state LPs in the state. The right-most send of columns presents the annual financial effects due to the difference in the performance of state LPs on their in-state investments versus the performance of the same LPs out of state.

\begin{tabular}{|c|c|c|c|c|c|c|c|c|}
\hline & \multirow[b]{2}{*}{$\begin{array}{c}\text { PE } \\
\text { Assets } \\
(\$ B)\end{array}$} & \multirow[b]{2}{*}{$\begin{array}{l}\text { Contributions } \\
(\$ \mathrm{~B})\end{array}$} & \multicolumn{3}{|c|}{$\begin{array}{c}\text { Annual Loss: LP(in)GP(in) - } \\
\text { LP(out)GP(in) }\end{array}$} & \multicolumn{3}{|c|}{$\begin{array}{c}\text { Annual Loss: LP(in)GP(in) - } \\
\text { LP(in)GP(out) }\end{array}$} \\
\hline & & & $\$ M$ & $\begin{array}{c}\text { Share } \\
\text { of PE } \\
\text { Assets }\end{array}$ & $\begin{array}{c}\text { Share of } \\
\text { Contributions } \\
\end{array}$ & $\$ M$ & $\begin{array}{c}\text { Share } \\
\text { of PE } \\
\text { Assets }\end{array}$ & $\begin{array}{c}\text { Share of } \\
\text { Contributions }\end{array}$ \\
\hline $\mathrm{CA}$ & 56.89 & 14.90 & $(670.3)$ & $-1.2 \%$ & $-4.5 \%$ & $(783.9)$ & $-1.4 \%$ & $-5.3 \%$ \\
\hline $\mathrm{CO}$ & 2.88 & 1.38 & 26.5 & $0.9 \%$ & $1.9 \%$ & 21.7 & $0.8 \%$ & $1.6 \%$ \\
\hline $\mathrm{CT}$ & 1.41 & 1.60 & $(22.1)$ & $-1.6 \%$ & $-1.4 \%$ & $(23.5)$ & $-1.7 \%$ & $-1.5 \%$ \\
\hline $\mathrm{DC}$ & 0.60 & 0.16 & $(2.5)$ & $-0.4 \%$ & $-1.6 \%$ & $(2.0)$ & $-0.3 \%$ & $-1.2 \%$ \\
\hline FL & 4.38 & 3.37 & 5.3 & $0.1 \%$ & $0.2 \%$ & 6.3 & $0.1 \%$ & $0.2 \%$ \\
\hline ID & 0.78 & 0.47 & 0.0 & $0.0 \%$ & $0.0 \%$ & $(0.3)$ & $0.0 \%$ & $-0.1 \%$ \\
\hline IL & 6.75 & 5.17 & $(38.3)$ & $-0.6 \%$ & $-0.7 \%$ & $(53.6)$ & $-0.8 \%$ & $-1.0 \%$ \\
\hline IN & 1.37 & 1.77 & (1.4) & $-0.1 \%$ & $-0.1 \%$ & $(2.9)$ & $-0.2 \%$ & $-0.2 \%$ \\
\hline MA & 5.87 & 2.38 & (293.9) & $-5.0 \%$ & $-12.4 \%$ & $(306.3)$ & $-5.2 \%$ & $-12.9 \%$ \\
\hline $\mathrm{MD}$ & 1.39 & 1.64 & (16.4) & $-1.2 \%$ & $-1.0 \%$ & $(15.0)$ & $-1.1 \%$ & $-0.9 \%$ \\
\hline MI & 8.07 & 1.74 & $(2.8)$ & $0.0 \%$ & $-0.2 \%$ & 1.8 & $0.0 \%$ & $0.1 \%$ \\
\hline $\mathrm{MN}$ & 3.50 & 1.53 & (3.8) & $-0.1 \%$ & $-0.3 \%$ & (4.6) & $-0.1 \%$ & $-0.3 \%$ \\
\hline $\mathrm{NC}$ & 7.07 & 1.94 & 18.0 & $0.3 \%$ & $0.9 \%$ & 40.5 & $0.6 \%$ & $2.1 \%$ \\
\hline NH & 0.06 & 0.34 & 0.0 & $0.0 \%$ & $0.0 \%$ & 0.1 & $0.2 \%$ & $0.0 \%$ \\
\hline NJ & 3.67 & 3.50 & 2.3 & $0.1 \%$ & $0.1 \%$ & 1.7 & $0.0 \%$ & $0.0 \%$ \\
\hline NY & 23.28 & 4.17 & (171.3) & $-0.7 \%$ & $-4.1 \%$ & 252.2 & $1.1 \%$ & $6.0 \%$ \\
\hline $\mathrm{OH}$ & 7.52 & 5.79 & $(40.8)$ & $-0.5 \%$ & $-0.7 \%$ & 13.9 & $0.2 \%$ & $0.2 \%$ \\
\hline OR & 9.26 & 0.66 & 0.0 & $0.0 \%$ & $0.0 \%$ & $(0.4)$ & $0.0 \%$ & $-0.1 \%$ \\
\hline PA & 14.95 & 2.02 & 83.1 & $0.6 \%$ & $4.1 \%$ & 36.0 & $0.2 \%$ & $1.8 \%$ \\
\hline RI & 0.59 & 0.56 & $(0.5)$ & $-0.1 \%$ & $-0.1 \%$ & 0.1 & $0.0 \%$ & $0.0 \%$ \\
\hline $\mathrm{TN}$ & 0.54 & 1.09 & 0.0 & $0.0 \%$ & $0.0 \%$ & $(13.0)$ & $-2.4 \%$ & $-1.2 \%$ \\
\hline TX & 10.33 & 6.78 & (81.7) & $-0.8 \%$ & $-1.2 \%$ & $(89.0)$ & $-0.9 \%$ & $-1.3 \%$ \\
\hline VA & 4.36 & 2.83 & $(0.2)$ & $0.0 \%$ & $0.0 \%$ & $(3.7)$ & $-0.1 \%$ & $-0.1 \%$ \\
\hline WA & 13.73 & 1.85 & (18.4) & $-0.1 \%$ & $-1.0 \%$ & 2.6 & $0.0 \%$ & $0.1 \%$ \\
\hline WI & 4.70 & 1.37 & 0.0 & $0.0 \%$ & $0.0 \%$ & 2.7 & $0.1 \%$ & $0.2 \%$ \\
\hline Total & 194 & 69 & $(1229.3)$ & $-0.6 \%$ & $-1.8 \%$ & $(918.6)$ & $-0.5 \%$ & $-1.3 \%$ \\
\hline
\end{tabular}


Figure 1: Performance of In-State and Out-of-State Investments in Terms of Net IRR, by LP Type

This figure presents the performance of in-state and out-of-state investments by LP type. T-statistics of statistical tests for the equality of in-state versus out of state performance are presented in the figure. The performance measure is net IRR adjusted by the mean net IRR of all investments in the sample that are made in the same state and vintage year.

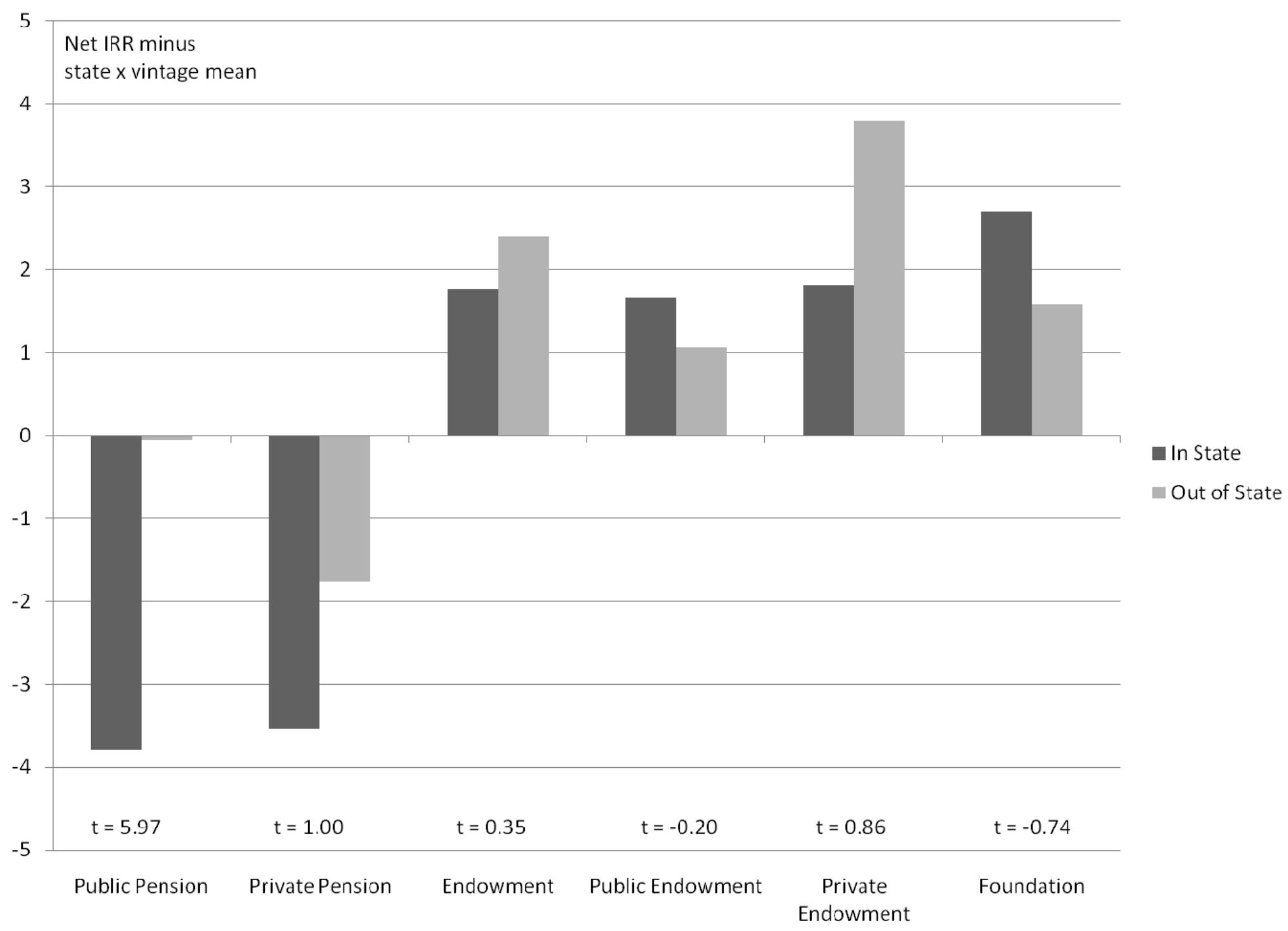


Figure 2: Performance of In-State and Out-of-State Investments in Terms of Net IRR, by LP Type

This figure presents the performance of in-state and out-of-state investments by LP type. T-statistics of statistical tests for the equality of in-state versus out of state performance are presented in the figure. The performance measure is net IRR adjusted by the mean net IRR of all investments in the sample that are made in the same state, vintage year and fund type.

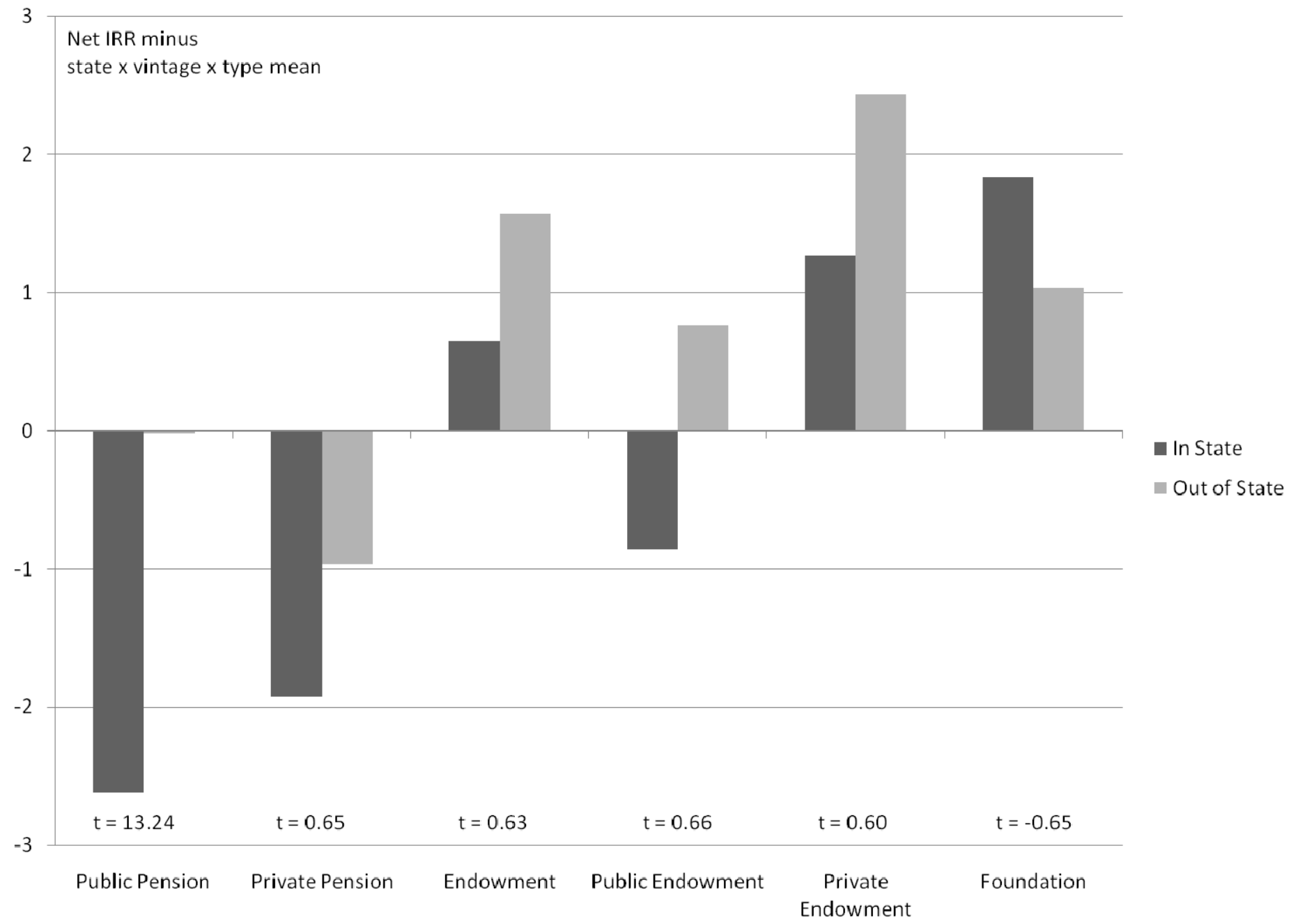


Figure 3: Performance of In-State and Out-of-State Investments in Terms of Net IRR, by LP Type

This figure presents the performance of in-state and out-of-state investments by LP type. T-statistics of statistical tests for the equality of in-state versus out of state performance are presented in the figure. The performance measure is multiple of invested capital adjusted by the mean multiple of invested capital of all investments in the sample that are made in the same state, vintage year and fund type.

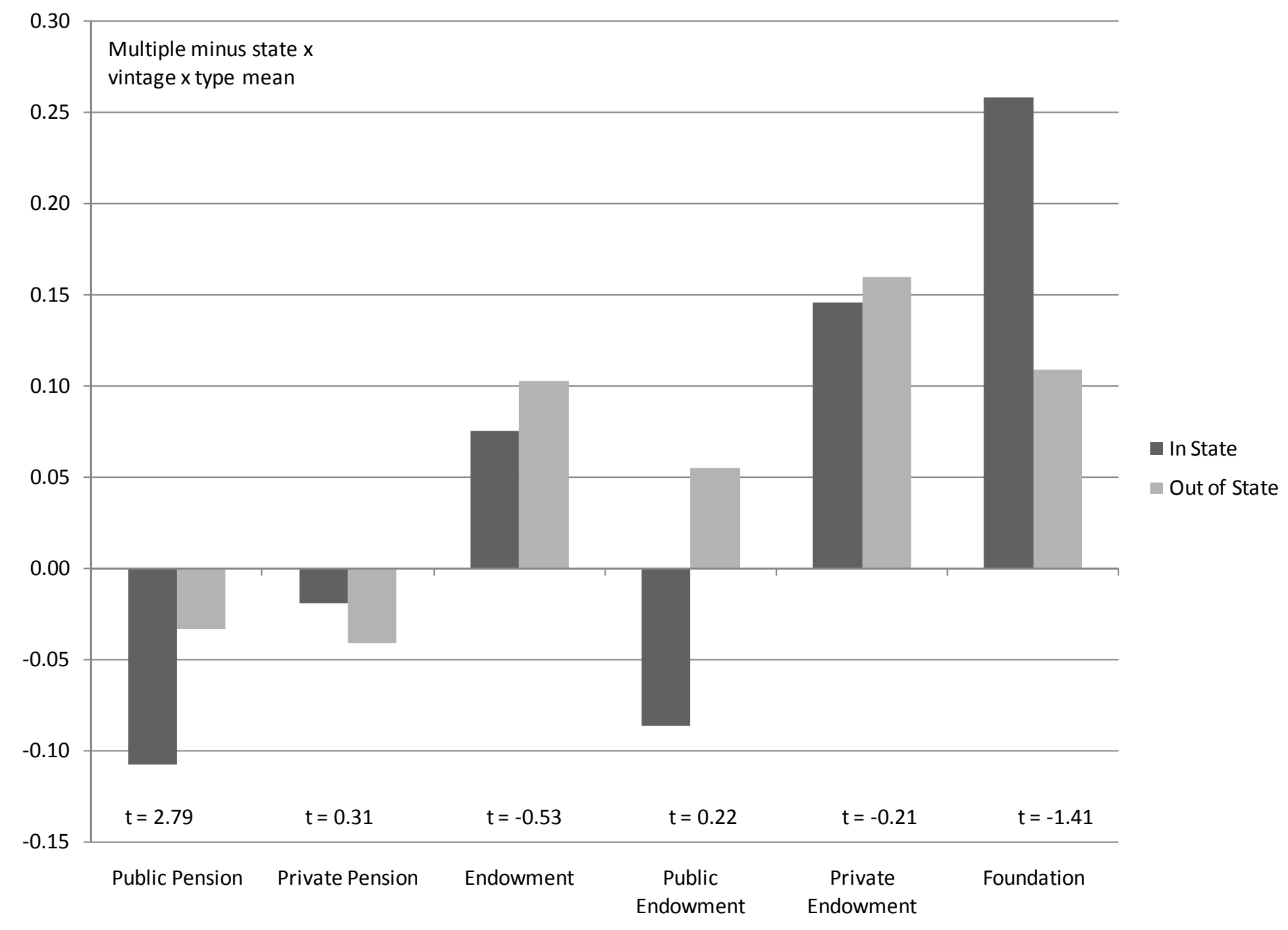


Figure 4: Underperformance of In-State Public Pension PE Investments by Category

The graph shows the relative performance of public pension PE investments in-state versus out-of-state by category, with a t-statistic for whether the performance is equal. Performance is measured as net IRR minus the mean of all other investments in the same vintage and GP state. T-statistics of statistical tests for the equality of in-state versus out of state performance are presented at the bottom of the figure.

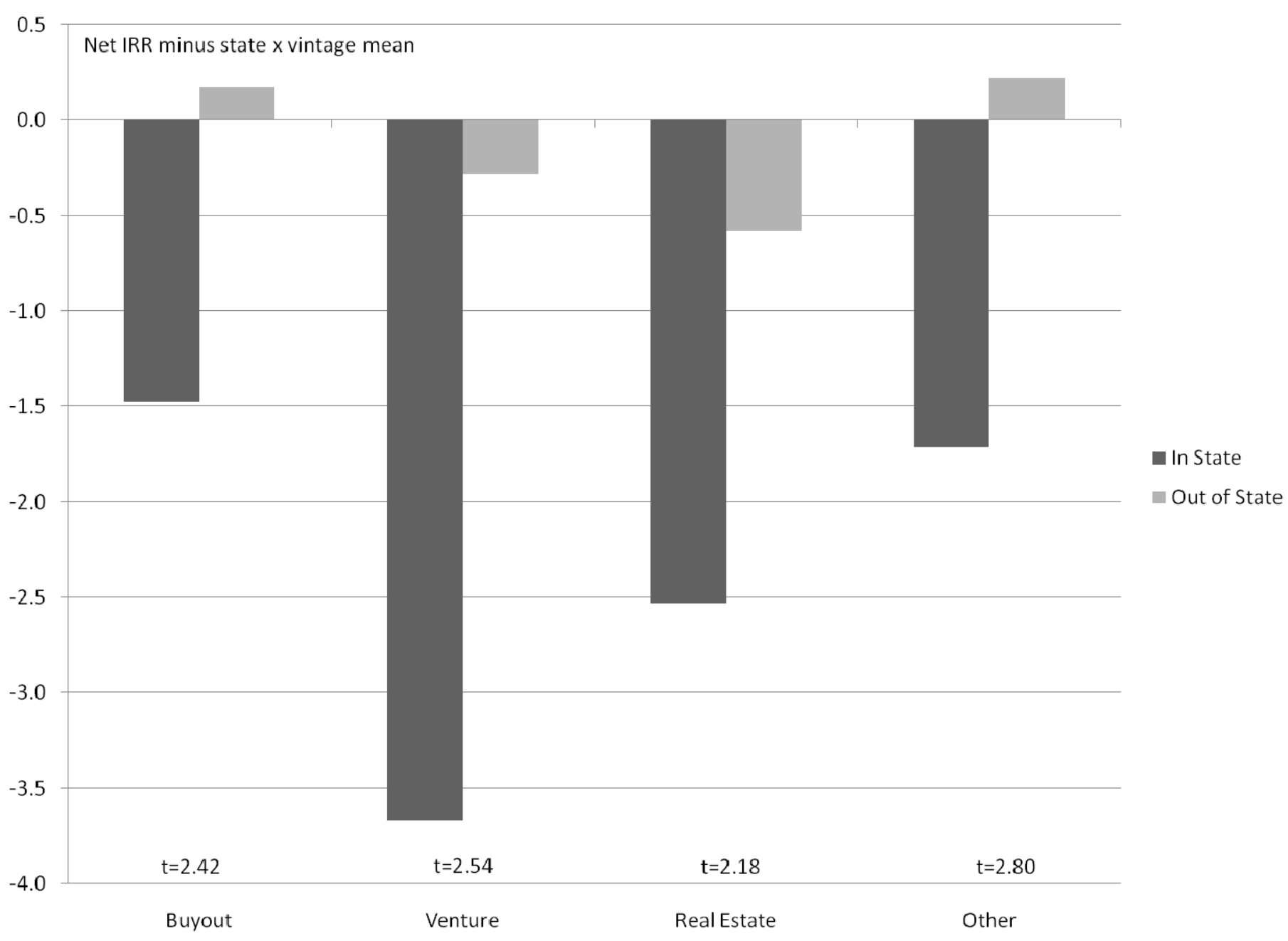




\section{Appendix Table 1: Geographical Distribution of Investments}

This table presents the geographical distribution of sample PE investments, by the state where the fund is headquartered. Nine states without PE investments are not shown: AK, HI, KS, MS, MT, ND, NV, SD, and WV. The first set of columns gives the total number of investments. The second set gives the total number of PE investments in the state by out-of-state LPs. The third set gives the number of PE investments by in-state LPs.

\begin{tabular}{|c|c|c|c|c|c|c|}
\hline \multirow[b]{3}{*}{ State(GP) } & \multicolumn{2}{|c|}{ Total } & \multicolumn{2}{|c|}{ by Out-of-State LPs } & \multicolumn{2}{|c|}{ by In-State LPs } \\
\hline & number & $\%$ & number & $\%$ & number & $\%$ \\
\hline & (1) & (2) & (3) & (4) & (5) & (6) \\
\hline $\mathrm{AL}$ & 2 & $0.01 \%$ & 2 & $0.01 \%$ & 0 & $0.00 \%$ \\
\hline AR & 1 & $0.01 \%$ & 0 & $0.00 \%$ & 1 & $0.03 \%$ \\
\hline $\mathrm{AZ}$ & 1 & $0.01 \%$ & 0 & $0.00 \%$ & 1 & $0.03 \%$ \\
\hline CA & 4,865 & $25.84 \%$ & 3,672 & $23.42 \%$ & 1,193 & $37.87 \%$ \\
\hline $\mathrm{CO}$ & 187 & $0.99 \%$ & 152 & $0.97 \%$ & 35 & $1.11 \%$ \\
\hline $\mathrm{CT}$ & 1,307 & $6.94 \%$ & 1,271 & $8.11 \%$ & 36 & $1.14 \%$ \\
\hline $\mathrm{DC}$ & 280 & $1.49 \%$ & 277 & $1.77 \%$ & 3 & $0.10 \%$ \\
\hline $\mathrm{DE}$ & 3 & $0.02 \%$ & 3 & $0.02 \%$ & 0 & $0.00 \%$ \\
\hline FL & 140 & $0.74 \%$ & 138 & $0.88 \%$ & 2 & $0.06 \%$ \\
\hline GA & 38 & $0.20 \%$ & 36 & $0.23 \%$ & 2 & $0.06 \%$ \\
\hline IA & 10 & $0.05 \%$ & 8 & $0.05 \%$ & 2 & $0.06 \%$ \\
\hline ID & 7 & $0.04 \%$ & 4 & $0.03 \%$ & 3 & $0.10 \%$ \\
\hline IL & 1,358 & $7.21 \%$ & 1,075 & $6.86 \%$ & 283 & $8.98 \%$ \\
\hline IN & 27 & $0.14 \%$ & 9 & $0.06 \%$ & 18 & $0.57 \%$ \\
\hline KY & 4 & $0.02 \%$ & 1 & $0.01 \%$ & 3 & $0.10 \%$ \\
\hline LA & 2 & $0.01 \%$ & 0 & $0.00 \%$ & 2 & $0.06 \%$ \\
\hline MA & 3,182 & $16.90 \%$ & 2,776 & $17.71 \%$ & 406 & $12.89 \%$ \\
\hline MD & 175 & $0.93 \%$ & 163 & $1.04 \%$ & 12 & $0.38 \%$ \\
\hline ME & 5 & $0.03 \%$ & 5 & $0.03 \%$ & 0 & $0.00 \%$ \\
\hline MI & 55 & $0.29 \%$ & 40 & $0.26 \%$ & 15 & $0.48 \%$ \\
\hline MN & 148 & $0.79 \%$ & 107 & $0.68 \%$ & 41 & $1.30 \%$ \\
\hline MO & 18 & $0.10 \%$ & 9 & $0.06 \%$ & 9 & $0.29 \%$ \\
\hline $\mathrm{NC}$ & 89 & $0.47 \%$ & 57 & $0.36 \%$ & 32 & $1.02 \%$ \\
\hline $\mathrm{NE}$ & 8 & $0.04 \%$ & 4 & $0.03 \%$ & 4 & $0.13 \%$ \\
\hline $\mathrm{NH}$ & 10 & $0.05 \%$ & 8 & $0.05 \%$ & 2 & $0.06 \%$ \\
\hline NJ & 253 & $1.34 \%$ & 245 & $1.56 \%$ & 8 & $0.25 \%$ \\
\hline NM & 3 & $0.02 \%$ & 2 & $0.01 \%$ & 1 & $0.03 \%$ \\
\hline NY & 4,400 & $23.37 \%$ & 3,853 & $24.58 \%$ & 547 & $17.37 \%$ \\
\hline $\mathrm{OH}$ & 293 & $1.56 \%$ & 172 & $1.10 \%$ & 121 & $3.84 \%$ \\
\hline OK & 27 & $0.14 \%$ & 27 & $0.17 \%$ & 0 & $0.00 \%$ \\
\hline OR & 22 & $0.12 \%$ & 15 & $0.10 \%$ & 7 & $0.22 \%$ \\
\hline PA & 307 & $1.63 \%$ & 163 & $1.04 \%$ & 144 & $4.57 \%$ \\
\hline RI & 153 & $0.81 \%$ & 142 & $0.91 \%$ & 11 & $0.35 \%$ \\
\hline $\mathrm{SC}$ & 1 & $0.01 \%$ & 0 & $0.00 \%$ & 1 & $0.03 \%$ \\
\hline $\mathrm{TN}$ & 42 & $0.22 \%$ & 36 & $0.23 \%$ & 6 & $0.19 \%$ \\
\hline TX & 1,087 & $5.77 \%$ & 938 & $5.98 \%$ & 149 & $4.73 \%$ \\
\hline UT & 9 & $0.05 \%$ & 7 & $0.04 \%$ & 2 & $0.06 \%$ \\
\hline VA & 124 & $0.66 \%$ & 117 & $0.75 \%$ & 7 & $0.22 \%$ \\
\hline VT & 9 & $0.05 \%$ & 9 & $0.06 \%$ & 0 & $0.00 \%$ \\
\hline WA & 154 & $0.82 \%$ & 129 & $0.82 \%$ & 25 & $0.79 \%$ \\
\hline WI & 21 & $0.11 \%$ & 5 & $0.03 \%$ & 16 & $0.51 \%$ \\
\hline WY & 1 & $0.01 \%$ & 1 & $0.01 \%$ & 0 & $0.00 \%$ \\
\hline Total & 18,828 & $100.00 \%$ & 15,678 & $100.00 \%$ & 3,150 & $100.00 \%$ \\
\hline Mean & & $1.96 \%$ & & $1.96 \%$ & & $1.96 \%$ \\
\hline Median & & $0.10 \%$ & & $0.06 \%$ & & $0.10 \%$ \\
\hline
\end{tabular}


Appendix Table 2: Geographical Distribution of Investments by Capital Committed

This table presents the geographical distribution of capital committed to PE investments, by the state where the fund is headquartered. Nine states without PE investments are not shown: AK, HI, KS, MS, MT, ND, NV, SD, and WV. Four states without known commitments are not shown: AL, AR, NM, and WY. The first set of columns gives the total dollar value of investments. The second set gives the total dollar value of PE investments in the state by out-of-state LPs. The third set gives the dollar value of PE investments by in-state LPs.

\begin{tabular}{|c|c|c|c|c|c|c|}
\hline \multirow[b]{3}{*}{ State(GP) } & \multicolumn{2}{|c|}{ Total } & \multicolumn{2}{|c|}{ by Out-of-State LPs } & \multicolumn{2}{|c|}{ by In-State LPs } \\
\hline & Dollars & Share & Dollars & Share & number & $\%$ \\
\hline & $(1)$ & $(2)$ & (3) & $(4)$ & $(5)$ & (6) \\
\hline AZ & 22 & $0.0 \%$ & 0 & $0.0 \%$ & 22 & $0.0 \%$ \\
\hline $\mathrm{CA}$ & 97,541 & $19.6 \%$ & 64,551 & $14.8 \%$ & 32,990 & $54.4 \%$ \\
\hline $\mathrm{CO}$ & 3,114 & $0.6 \%$ & 2,647 & $0.6 \%$ & 467 & $0.8 \%$ \\
\hline $\mathrm{CT}$ & 28,943 & $5.8 \%$ & 26,684 & $6.1 \%$ & 2,259 & $3.7 \%$ \\
\hline $\mathrm{DC}$ & 16,103 & $3.2 \%$ & 16,067 & $3.7 \%$ & 35 & $0.1 \%$ \\
\hline $\mathrm{DE}$ & 13 & $0.0 \%$ & 13 & $0.0 \%$ & 0 & $0.0 \%$ \\
\hline FL & 1,258 & $0.3 \%$ & 1,243 & $0.3 \%$ & 15 & $0.0 \%$ \\
\hline GA & 528 & $0.1 \%$ & 528 & $0.1 \%$ & 0 & $0.0 \%$ \\
\hline IA & 389 & $0.1 \%$ & 379 & $0.1 \%$ & 10 & $0.0 \%$ \\
\hline ID & 60 & $0.0 \%$ & 32 & $0.0 \%$ & 28 & $0.0 \%$ \\
\hline IL & 22,395 & $4.5 \%$ & 19,007 & $4.4 \%$ & 3,388 & $5.6 \%$ \\
\hline $\mathrm{IN}$ & 161 & $0.0 \%$ & 114 & $0.0 \%$ & 47 & $0.1 \%$ \\
\hline KY & 24 & $0.0 \%$ & 0 & $0.0 \%$ & 24 & $0.0 \%$ \\
\hline LA & 11 & $0.0 \%$ & 0 & $0.0 \%$ & 11 & $0.0 \%$ \\
\hline MA & 50,952 & $10.3 \%$ & 49,185 & $11.3 \%$ & 1,767 & $2.9 \%$ \\
\hline MD & 2,714 & $0.5 \%$ & 2,566 & $0.6 \%$ & 148 & $0.2 \%$ \\
\hline ME & 4 & $0.0 \%$ & 4 & $0.0 \%$ & 0 & $0.0 \%$ \\
\hline MI & 715 & $0.1 \%$ & 490 & $0.1 \%$ & 225 & $0.4 \%$ \\
\hline $\mathrm{MN}$ & 7,267 & $1.5 \%$ & 6,148 & $1.4 \%$ & 1,119 & $1.8 \%$ \\
\hline MO & 47 & $0.0 \%$ & 35 & $0.0 \%$ & 12 & $0.0 \%$ \\
\hline $\mathrm{NC}$ & 2,102 & $0.4 \%$ & 1,397 & $0.3 \%$ & 705 & $1.2 \%$ \\
\hline $\mathrm{NE}$ & 310 & $0.1 \%$ & 290 & $0.1 \%$ & 20 & $0.0 \%$ \\
\hline $\mathrm{NH}$ & 42 & $0.0 \%$ & 28 & $0.0 \%$ & 14 & $0.0 \%$ \\
\hline NJ & 6,023 & $1.2 \%$ & 5,773 & $1.3 \%$ & 250 & $0.4 \%$ \\
\hline NY & 189,079 & $38.1 \%$ & 183,127 & $42.0 \%$ & 5,952 & $9.8 \%$ \\
\hline $\mathrm{OH}$ & 3,228 & $0.6 \%$ & 1,812 & $0.4 \%$ & 1,416 & $2.3 \%$ \\
\hline OK & 141 & $0.0 \%$ & 141 & $0.0 \%$ & 0 & $0.0 \%$ \\
\hline OR & 791 & $0.2 \%$ & 644 & $0.1 \%$ & 147 & $0.2 \%$ \\
\hline PA & 8,081 & $1.6 \%$ & 4,381 & $1.0 \%$ & 3,700 & $6.1 \%$ \\
\hline RI & 7,469 & $1.5 \%$ & 7,323 & $1.7 \%$ & 146 & $0.2 \%$ \\
\hline $\mathrm{SC}$ & 20 & $0.0 \%$ & 0 & $0.0 \%$ & 20 & $0.0 \%$ \\
\hline $\mathrm{TN}$ & 194 & $0.0 \%$ & 194 & $0.0 \%$ & 0 & $0.0 \%$ \\
\hline $\mathrm{TX}$ & 42,502 & $8.6 \%$ & 37,862 & $8.7 \%$ & 4,640 & $7.6 \%$ \\
\hline UT & 50 & $0.0 \%$ & 45 & $0.0 \%$ & 5 & $0.0 \%$ \\
\hline VA & 2,923 & $0.6 \%$ & 2,514 & $0.6 \%$ & 409 & $0.7 \%$ \\
\hline VT & 130 & $0.0 \%$ & 130 & $0.0 \%$ & 0 & $0.0 \%$ \\
\hline WA & 1,181 & $0.2 \%$ & 813 & $0.2 \%$ & 368 & $0.6 \%$ \\
\hline WI & 390 & $0.1 \%$ & 95 & $0.0 \%$ & 295 & $0.5 \%$ \\
\hline Total & 496,917 & $100 \%$ & 436,262 & $100 \%$ & 60,654 & $100 \%$ \\
\hline mean & & $2.56 \%$ & & $2.56 \%$ & & $2.56 \%$ \\
\hline median & & $0.14 \%$ & & $0.12 \%$ & & $0.08 \%$ \\
\hline
\end{tabular}




\section{Appendix Table 3: Net IRR Differences, Weighted by Size of Commitment}

This table is analogous to a value-weighted version of Table 8. It shows t-tests of differences in net IRR between in-state and out-of-state investments, where the means are weighted by the size of the LP's commitment. The left panel analyzes the raw IRR, and the right panel examines the IRR minus the mean of all other observations in the same state and vintage of the investment fund (the GP). For some LP types, including private pensions and private endowments the joint coverage of net IRR and LP commitment size would result in extremely small sample sizes, and hence these LP types are not shown.

All

\begin{tabular}{llrr} 
& & & IRR \\
\cline { 3 - 4 } & & \multicolumn{2}{c}{ Out of } \\
All & & State & In State \\
\cline { 3 - 4 } & $\mu$ & 2.23 & -1.25 \\
& $\mathrm{~N}$ & 7390 & 143 \\
& & & \\
Public Pension & $\mu$ & 2.15 & -1.43 \\
& $\mathrm{~N}$ & 6643 & 134
\end{tabular}

IRR

Endowment

$\begin{array}{lr}\mu & 6.28 \\ \mathrm{~N} & 688\end{array}$

$$
\begin{array}{r}
5.88 \\
75
\end{array}
$$

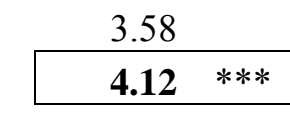

0.12

$\begin{array}{lr}\mu & 6.30 \\ \mathrm{~N} & 673\end{array}$

5.88

75

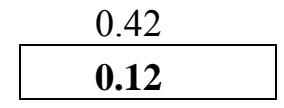

8.94

2.92

$\mathrm{N} \quad 61$
$-0.92$

6643

1.07

688

1.11

673

IRR Minus State x Vintage Mean

Out of

State In State Difference

$-0.89$

$-4.42$

1431 3.54

$5.78 * * *$

\begin{tabular}{llll}
7390 & $1431 \quad \mathbf{5 . 7 8}$ & $* * *$ \\
\hline
\end{tabular}

\begin{tabular}{l|l|}
-4.62 & 3.70 \\
1342 & $\mathbf{5 . 8 2}$
\end{tabular}

\begin{tabular}{rr}
3.47 & -2.40 \\
75 & $\mathbf{0 . 8 3}$ \\
\hline
\end{tabular}

\begin{tabular}{rr}
3.47 & -2.36 \\
75 & $\mathbf{0 . 8 1}$ \\
\cline { 2 - 2 }
\end{tabular}

0.14
61

-0.15
14

0.28 